$5-15-2020$

\title{
Adolescent Girls Initiative-Kenya: Endline evaluation report
}

\author{
Karen Austrian \\ Population Council \\ Erica Soler-Hampejsek \\ Beth Kangwana \\ Population Council \\ Nicole Maddox \\ Population Council \\ Yohannes Dibaba Wado
}

See next page for additional authors

Follow this and additional works at: https://knowledgecommons.popcouncil.org/departments_sbsr-pgy

Part of the International Public Health Commons, and the Social and Behavioral Sciences Commons How does access to this work benefit you? Let us know!

\section{Recommended Citation}

Austrian, Karen, Erica Soler-Hampejsek, Beth Kangwana, Nicole Maddox, Yohannes Dibaba Wado, Benta Abuya, Valsa Shah, and John A. Maluccio. 2020. "Adolescent Girls Initiative-Kenya: Endline evaluation report." Nairobi: Population Council. 


\section{Authors}

Karen Austrian, Erica Soler-Hampejsek, Beth Kangwana, Nicole Maddox, Yohannes Dibaba Wado, Benta Abuya, Valsa Shah, and John A. Maluccio 


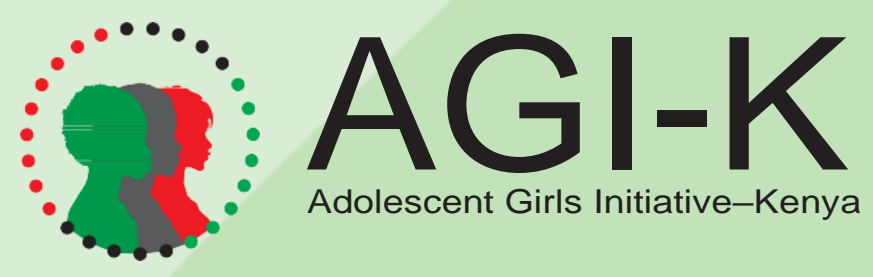

\section{Adolescent Girls Initiative-Kenya \\ ENDLINE EVALUATION REPORT}

MAY 2020 


\title{
POPULATION
}

COUNCIL

Ideas. Evidence. Impact.

The Population Council confronts critical health and development issues-from stopping the spread of HIV to improving reproductive health and ensuring that young people lead full and productive lives. Through biomedical, social science, and public health research in 50 countries, we work with our partners to deliver solutions that lead to more effective policies, programs, and technologies that improve lives around the world. Established in 1952 and headquartered in New York, the Council is a nongovernmental, nonprofit organization governed by an international board of trustees.

\author{
Population Council \\ Avenue 5, 3rd Floor \\ Rose Avenue \\ PO Box 17643-00500 \\ Nairobi \\ Kenya
}

Tel: +254205134700

Email: info.nairobi@popcouncil.org

popcouncil.org

Suggested citation: Austrian, K., Soler-Hampejsek, E., Kangwana, B., Maddox, N., Wado, Y., Abuya, B., Shah, V., and Maluccio, J. 2020. “Adolescent Girls Initiative-Kenya: Endline Evaluation Report.” Nairobi: Population Council.

(C) 2020 The Population Council, Inc.

$\begin{array}{lll}\begin{array}{l}\text { AUTHORS } \\ \text { Karen Austrian, PhD, MPH }\end{array} & \text { Nicole Maddox, PhD } & \\ \begin{array}{l}\text { Senior Associate } \\ \text { Population Council, Kenya } \\ \text { kaustrian@popcouncil.org }\end{array} & \begin{array}{l}\text { Benta A. Abuya, PhD } \\ \text { Population Council, Kenya }\end{array} & \begin{array}{l}\text { Research Scientist } \\ \text { APHRC }\end{array} \\ \begin{array}{l}\text { Erica Soler-Hampejsek, PhD } \\ \text { Independent Consultant }\end{array} & \begin{array}{l}\text { Senior Consultant } \\ \text { Spain }\end{array} & \text { John Maluccio, PhD } \\ \text { Itad } & \text { Professor of Economics } \\ \text { Beth Kangwana, PhD } & \text { Yohannes Dibaba Wado, PhD } & \text { Middlebury College } \\ \text { Penior Program Officer } & \text { Associate Research Scientist } & \\ & \text { APHRC } & \\ & & \end{array}$

Prepared March 2020. This is a technical paper and represents research in progress. This paper represents the opinions of the authors and is the product of professional research. This paper has not been peer reviewed, and this version may be updated with additional analyses in subsequent publications. 


\section{Table of Contents}

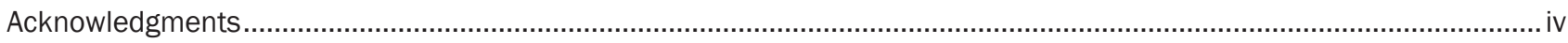

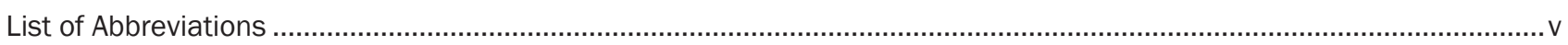

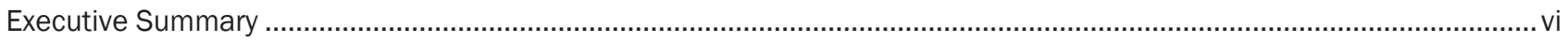

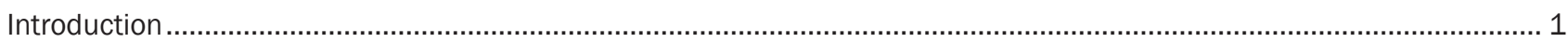

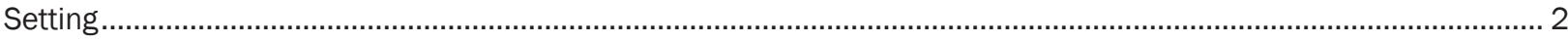

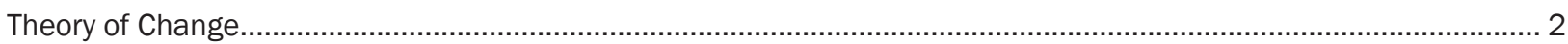

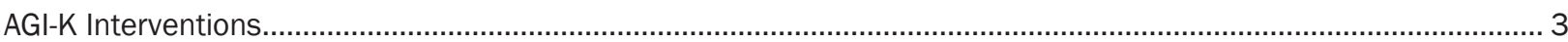

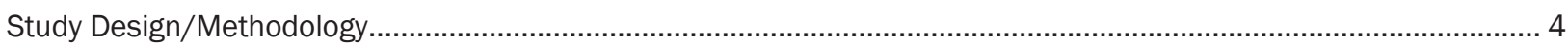

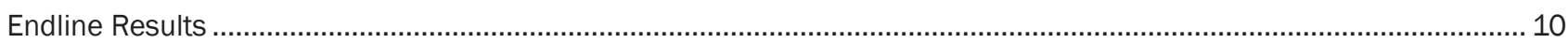

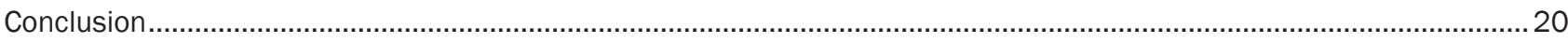

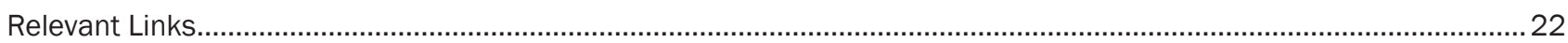

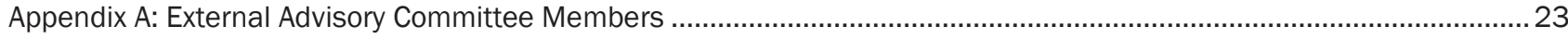

Appendix B: Intent-to-Treat (ITT) Endline Indicators Analysis Tables (Kibera) .............................................................25

Appendix C: Intent-to-Treat (ITT) Endline Indicators Analysis Tables (Wajir) ..................................................................26

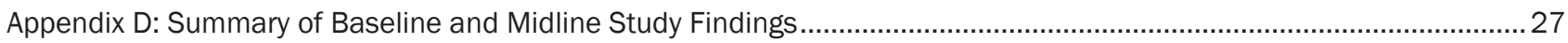

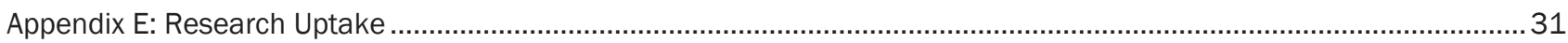

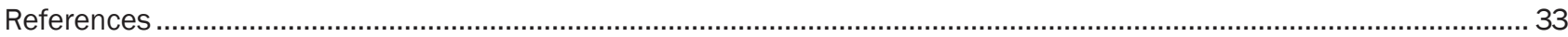




\section{Acknowledgments}

The Adolescent Girls Initiative-Kenya (AGI-K) endline report would not be possible without the hard work of the project partners and research teams dedicated to improving the lives of vulnerable adolescent girls. AGI-K is implemented by a consortium led by the Population Council, with the African Population and Health Research Center (APHRC) as a research partner, Save the Children as implementing partner in Wajir, Plan International as implementing partner in Kibera, and Itad as consultant on the cost-effectiveness and benefits valuation. We would like to thank all of the project members as well as the members of the AGI-K National External Advisory Committee (EAC) and the Kibera and Wajir EACs for their invaluable input into the interpretation of the endline results (see Appendix A).

We would like to acknowledge the efforts of the large team of dedicated research assistants and supervisors who collected the data, with the endline led by James Joseph in Kibera and James Serembe in Wajir. The entire exercise was coordinated by AGI-K Data and Field Study Coordinators Eva Muluve and Faith Mbushi, with logistical support by Joyce Ombeva, based in the Population Council office in Kenya. We thank Lizzie Friesen of Middlebury College for her careful work cleaning the endline data. We are also grateful for the contributions of Eunice Muthengi to the inception and implementation of the study while she was a staff member at the Population Council. We similarly thank Caroline Kabiru and Joyce Mumah, formerly of the African Population and Health Research Center (APHRC), for contributions in earlier phases of the study. We thank Charles Gatama for programming the survey tools for electronic data capture and Daniel Koma and Lilian Nduku for supervising and coordinating the biomarker data collection. We also thank AGI-K Program Staff from Save the Children-Joyce Kimani, Evans Kibet, Hassan Mohammed, and Abdullahi Aden-and Joy Koech and Phanuel Owiti of Plan International, for overall management and oversight of interventionactivities.

The authors thank the UK Department for International Development (DFID) for investing in rigorous research that will provide evidence to influence national policy and will support scaled-up, cost-effective interventions for adolescent girls in the future. We also thank those from DFID-Kenya and the AGI-K Expert Research Committee who provided feedback on drafts of this report.

Finally, we are grateful to the adolescent girls and their parents/guardians who participated in the research and took the time to share their thoughts and experiences with us. 


\section{List of Abbreviations}

AGI-K - Adolescent Girls Initiative-Kenya

AMREF - African Medical and Research Foundation

APHRC - African Population and Health Research Center

ASAL - Arid and Semi-arid Land

CAPI - Computer-Assisted Personal Interviewing

CC - Community Conversation

CCT - Conditional Cash Transfer

DFID - Department for International Development

EAC - External Advisory Committee

FE - Financial Education

FGD - Focus Group Discussion

GDP - Gross Domestic Product

HIV - Human Immunodeficiency Virus

ICA - Intercoder Agreement

IDI - In-depth Interview

IPV - Intimate Partner Violence

IRB - Institutional Review Board

ITT - Intent-to-Treat

KES - Kenya Shillings

RCT - Randomized Controlled Trial

SRH - Sexual and Reproductive Health

SRHR - Sexual and Reproductive Health and Rights

STI - Sexually Transmitted Infection 


\section{Executive Summary}

\section{INTRODUCTION}

Early pregnancy is a challenge for girls in Kenya that often has immediate effects on their educational opportunities, future implications for their social, health, and economic outcomes, and negative impacts on their children. However, early pregnancy is an outcome shaped by a myriad of issues affecting an adolescent girl's lifeincluding community norms on gender roles, violence, and the value of girls; barriers to formal education; household poverty; lack of economic independence; experience of violence; and social isolation. For girls to achieve well-being in early and late adolescence, no single-sector intervention-whether it be education, health, wealth creation, or the prevention of violence-will be adequate.

The Adolescent Girls Initiative-Kenya (AGI-K) delivered multi-sectoral interventions to over 6,000 girls ages 11-15 in two marginalized areas of Kenya: 1) the Kibera informal settlement in Nairobi and 2) Wajir County in Northeastern Kenya. Implemented by Plan International in Kibera and Save the Children in Wajir, these interventions were carried out for two years (2015 to 2017) and comprised a combination of girl-level, household-level, and community-level interventions. The hypothesis is that these interventions would build girl-level social, education, health, and economic assets, as well as improve household economic assets in the medium term, which will lead to delayed childbearing in the longer term.

The goal of AGI-K is unique in that it tests packages of four multi-sectoral interventions, rather than only singlesector intervention. The Violence Prevention (V) intervention included community dialogues and action plans where a key group of adult stakeholders in each community met regularly to discuss the challenges facing girls in their area and develop and implement a plan to address at least one of those challenges. The Education (E) intervention was a conditional cash transfer (CCT) that included a bimonthly payment to the household, direct payment of a portion of school fees, and a schooling kit for the girls; all incentives were conditioned on girls' enrollment and regular attendance at school. The Health $(\mathrm{H})$ intervention included weekly girls' group meetings, or safe spaces, facilitated by a young woman from the community that covered a range of health and life-skills topics. The Wealth Creation (W) intervention included financial education (FE) within the group meetings, as well as savings accounts in the urban site and home banks in the rural site.

A randomized controlled trial $(\mathrm{RCT})$ was used to compare the impact of three different packages of multi-sectoral interventions relative to a single community-level intervention, together with their costs, to assess if and how intervening in early adolescence will impact girls' life chances. AGI-K implemented the following packages:

1) Violence Prevention (V-only)

2) Violence Prevention + Education (VE)

3) Violence Prevention + Education + Health (VEH)

4) Violence Prevention + Education + Health + Wealth Creation (VEHW/full program package)

\section{Kibera Results}

At the end of the two-year intervention, ${ }^{1}$ girls in the three packages with CCT had improved rates of primary school completion and transition to secondary school for those in the final two years of primary school at the start of the intervention, as well as household wealth status. The health component improved a range of sexual and reproductive health $(\mathrm{SRH})$ knowledge measures, condom self-efficacy, and social safety nets, although it did not affect the acceptability of intimate partner violence (IPV) or equitable gender norms. The wealth component

\footnotetext{
${ }^{1}$ For the detailed midline results, reflecting change at the end of the two-year intervention, see the full Midline Report.
} 
improved financial literacy and savings behavior. An important note is that for girls who actively participated in safe spaces (health and wealth creation), the impact on their health and wealth outcomes was larger, as was the impact on their education outcomes-implying that participating in girls' groups with combined health and economic content had spillover effects onto their educational attainment.

Two years after the intervention, the CCT had an impact on delaying sexual debut and pregnancy by $27 \%$ and $43 \%$, respectively. In addition, there was a modest increase of $5 \%$ on primary school completion and transition to secondary school. Finally, households that had received the CCT had $7 \%$ relative higher wealth status. While the health intervention did not have a sustained impact on the quantitative measures after the intervention ended, the qualitative data that was collected one year after the intervention indicated that girls who participated in the girls' groups retained a sense of confidence, assertiveness, and voice. The wealth intervention led to a 33\% increase in long term savings behavior relative to the control.

\section{Wajir Results}

At the end of the two-year intervention, the CCT had a strong impact on primary school enrollment for all girls, as well as literacy and numeracy skills. The health component did not have an impact on SRH knowledge, but it did lead to modest improvements in gender norms. The wealth component improved financial literacy and savings behavior. Similar to Kibera, effect sizes on all education, health, and wealth outcomes were larger for girls who actively participated in the health and wealth components.

Two years after the intervention, for girls who were out of school at baseline, the CCT led to long-term improvements in delayed marriage (50\% v. 30\%) and pregnancy (34\% v. 17\%). There was also sustained school enrollment (16\% vs. 45\%), as well as improved literacy and numeracy. While the health component did not have any quantitative impacts two years after the program ended, the qualitative data did show perceived sustained gains in nutrition and hygiene knowledge. Finally, the wealth component had a positive impact on increased savings behavior in the long term.

\section{Cost Effectiveness and Benefits Valuation}

The conclusion from the midline results on value for money is that when the objective is to maximize girls' welfare on a range of indicators, it is more cost-effective to use a multi-sectoral approach.

The benefit valuation calculated a monetary benefit of $\$ 55$ per girl in Kibera and \$94 per out-of-school girl in Wajir. While these figures are less than the cost per girl during implementation, there are several factors to consider. First, this amount is a significant underestimation as it does not account for the benefits that are qualitative or otherwise unquantifiable in nature (e.g., confidence, voice, and choice), and therefore unable to be assigned a monetary value. Second, if the program was scaled up to all girls in Nairobi slums and the arid and semi-arid land (ASAL) counties in Kenya, there would be a total benefit of $\$ 27,783,289$ and the cost of implementation would be significantly reduced.

\section{Conclusions}

Overall, the two-year follow-up results largely confirmed the AGI-K theory of change and held up the view that an investment in early adolescents among the right groups of marginalized girls would have short-term benefits on asset accumulation, educational attainment, and household economic status that translated into longer-term impact on delaying childbearing. In addition, the causal mechanisms for delaying childbearing proposed-delaying sexual debut in Kibera and delaying marriage in Wajir-were also confirmed by the long-term results, albeit in Wajir only for the girls who were out of school at baseline.

The cash transfer appeared to be a key driver in the impact seen not only on education outcomes but also on delaying sexual debut and pregnancy in Kibera, as well as delaying marriage and pregnancy in Wajir. It appears that the path to these longer-term outcomes came largely through keeping girls in school in Kibera during the transition 
from primary to secondary school, and via getting girls who were out of school in Wajir into school, for many for the first time, and off the path to marriage.

However, there may still be value in offering the cash transfer together with girls empowerment groups that offer both health and economic empowerment. In particular, in the urban setting the economic components led to longterm, sustained improvements in savings behavior. Second, at the end of the two-year intervention, there were improvements in girls' confidence, voice, and sense of choice over their decisions. That the measures of empowerment did not show sustained impact two years after the programs suggests perhaps that maintaining social support for vulnerable girls and creating spaces in which they can learn about their rights and have opportunities to express themselves may need to be carried out over longer periods of time, whereas cash transfers can still be effective if delivered only during critical windows of vulnerability for girls and/or for particular sub-segments of girls. Beyond that, offering girls health and life-skills training can also be considered a right, as learning about their body, sexual and reproductive health and rights (SRHR), and life skills is mentioned in the United Nations Convention on the Rights of the Child. The cost-effectiveness calculations at midline (see Relevant Links, Midline Results Report) demonstrated that delivering the interventions in packages is better value for money than delivering them individually. Therefore, the fully combined package should still be considered based on impact, cost, and rights.

Another clear takeaway from the results is that targeting the intervention to particular sub-segments of girls is important. For example, in Wajir the strong impact was seen in girls who were out of school at baseline, which was a significant proportion of the sample. From that a possible conclusion is that a program like AGI-K in ASAL areas must be sure to reach those girls who are out of school as a jump-start to getting them back into school and off the path to child marriage, or those at risk of dropping out to ensure that they stay on that path. In Kibera, at midline the results on education were strongest for those in the final two years of primary school, and at endline the impact on delaying sexual debut was concentrated in the girls who were 13-15 years old at baseline. This suggests that perhaps in an urban informal settlement setting, the key sub-segment for target is those girls approaching midadolescence, about to enter that risky period of transitioning from primary to secondary school, and that the support during that window of vulnerability is key in keeping them on the path to completing secondary school and avoiding pregnancy in adolescence.

One of the key theories being tested was that it would take a multi-level, multi-sectoral program implemented in early adolescence to affect change in later adolescence. This means that the combination of interventions at girl, household, and community levels, addressing violence, education, health, and economic empowerment, would be needed to achieve higher-level results such as delayed childbearing. The evidence and experience of AGI-K suggests that this theory may be true, and that neither single-intervention programs nor programs that focus all of their interventions on one layer of the girls' ecosystem will create the necessary change in early adolescence to lead to longer-term impact. It is likely that the true benefit, in particular from a cost perspective, will be realized when the critical program components are able to operate at scale, at lower costs, and combine longer-term programming to sustain empowerment outcomes, with targeted cash incentives for vulnerable sub-populations of girls at their times of greatest risk. 


\section{Introduction}

Early pregnancy is a challenge for girls in Kenya that often has immediate effects on their educational opportunities, future implications for their social, health, and economic outcomes, and negative impacts on their children. For example, nearly one-quarter of women in Kenya have given birth by age 18 and almost half by age 20 (KNBS and ICF International 2015). Of women aged 20-29 who gave birth before age 20 , only $58 \%$ completed primary school (class 8 ) as compared to $87 \%$ of women who did not begin childbearing before age 20 . In addition, women who give birth early are more likely to have a larger number of children and lower income earning power, and their children are more likely to have poorer health outcomes (Wodon et al. 2017).

However, early pregnancy is an outcome shaped by a myriad of issues shaping an adolescent girl's life, including community norms on gender roles, violence, and the value of girls, barriers to formal education, household poverty, lack of economic independence, the experience of violence, and social isolation. Starting in early adolescence, girls living in marginalized environments face an intertwined set of challenges that set them on the course to experience multiple negative events that both result in, or follow from, early pregnancy. Therefore, it is critical to intervene before the myriad of issues that girls face result in outcomes that are irreversible or are costly to compensate for or reverse.

The root causes of these vulnerabilities work in tandem to create the current situation for adolescent girls-cultural norms that do not empower women and girls, acceptance of violence, poverty, social isolation, economic vulnerability, lack of voice in society-and therefore the interventions that will enable girls in early adolescence to make a safe and healthy transition through adolescence and into adulthood must be integrated as well. For girls to achieve well-being in early and late adolescence, no single-sector intervention-whether education, health, wealth creation, or prevention of violence-will be adequate.

The Adolescent Girls Initiative-Kenya (AGI-K) delivered multi-sectoral interventions to over 6,000 girls ages 11-15 in two marginalized areas of Kenya between 2015 and 2017:1) the Kibera informal settlement in Nairobi and 2) Wajir County in Northeastern Kenya. Implemented by Plan International in Kibera and Save the Children in Wajir, these interventions were carried out for two years and comprised a combination of girl-level, household-level, and communitylevel interventions. The interventions took into account the numerous complex, multifaceted, and interrelated factors that influence the well-being of very young adolescents living in varying geographies in urban and rural Kenya. The rationale for such an initiative that combines health, wealth, education, and violence prevention is that when the diverse asset base is fully realized, it will lead to increased educational attainment, and social, health, and economic assets, which will in turn result in less early pregnancy.

An RCT is used to compare the shorter- and longer-term impacts of three different packages of interventions relative to a single community-level intervention, together with their costs, to assess if and how intervening in early adolescence will impact girls' life chances in mid- and late adolescence. The overall purpose of the evaluation is to learn and add to the body of literature on what works to improve outcomes for adolescent girls, both in Kenya and globally. The information here can be used by policymakers, donors, and program planners who are interested in using evidence-based program design.

This report briefly describes both the intervention and research design of AGI-K, and presents the impact findings from the two-year follow-up data from Kibera, an urban informal settlement in Nairobi, and rural areas of Wajir County. The objective is to describe and compare the impact of the different program packages two years after program completion. 


\section{SETTING}

Urban informal settlements in Nairobi are characterized by high population density, lack of government services, high crime rates, lack of proper sewage and sanitation, and frequent in- and out-migration. Adolescent girls in Nairobi's informal settlements face a range of poor outcomes, as $45 \%$ of girls aged $18-20$ have given birth, and $43 \%$ of 15- to 19-year-olds are out of school. Kibera is one of Nairobi's largest informal settlements, with approximately 350,000 residents living in about six $\mathrm{km}^{2}$.

In contrast, Wajir County is one of the most underdeveloped counties in Kenya, covering over $55,000 \mathrm{~km}^{2}$ of arid land with a very low population density. Half of women ages 20-24 were married by age 18, less than a quarter of the adult population is literate, and in $201525 \%$ of adolescent girls aged 11-14 were out of school. However, it is an area of rapid change, as $99 \%$ of adolescents' parents had never been to school.

\section{THEORY OF CHANGE}

The interventions for AGI-K were based on a combination of the Asset Building Theory of Change that posits that girls need a combination of education, social, health, and economic assets to make a safe, healthy, and productive transition from childhood into young adulthood (Bruce and Sebstad 2005; Austrian and Ghati 2010), as well as the ecological framework for adolescent health (Blum et al. 2012), which takes into account multiple levels in an adolescent's world as influencers of adolescent well-being outcomes. The AGI-K theory of change (see Figure 1) outlines how the four intervention components will delay childbearing by delaying sexual debut and/or increasing contraceptive use in Kibera and by delaying marriage in Wajir. The mechanisms for change to achieve those primary outcomes are different in each site, but in both places include changes at the girl, household, and community level including social, health, and economic asset building, increased educational attainment, improved household economic status, and improved gender norms at the community level. In Wajir, the causal mechanisms were hypothesized to be improved community and household norms on the timing of marriage, increased educational enrollment and attainment for girls, lower economic need at the household level to marry girls, and improved selfefficacy for girls. In Kibera, the causal mechanisms were hypothesized to be increased educational attainment for girls, reductions in nonconsensual, nonprotected sex, reductions in sexual activity driven by economic needs, and improved self-efficacy for girls.

FIGURE 1. AGI-K Theory of Change

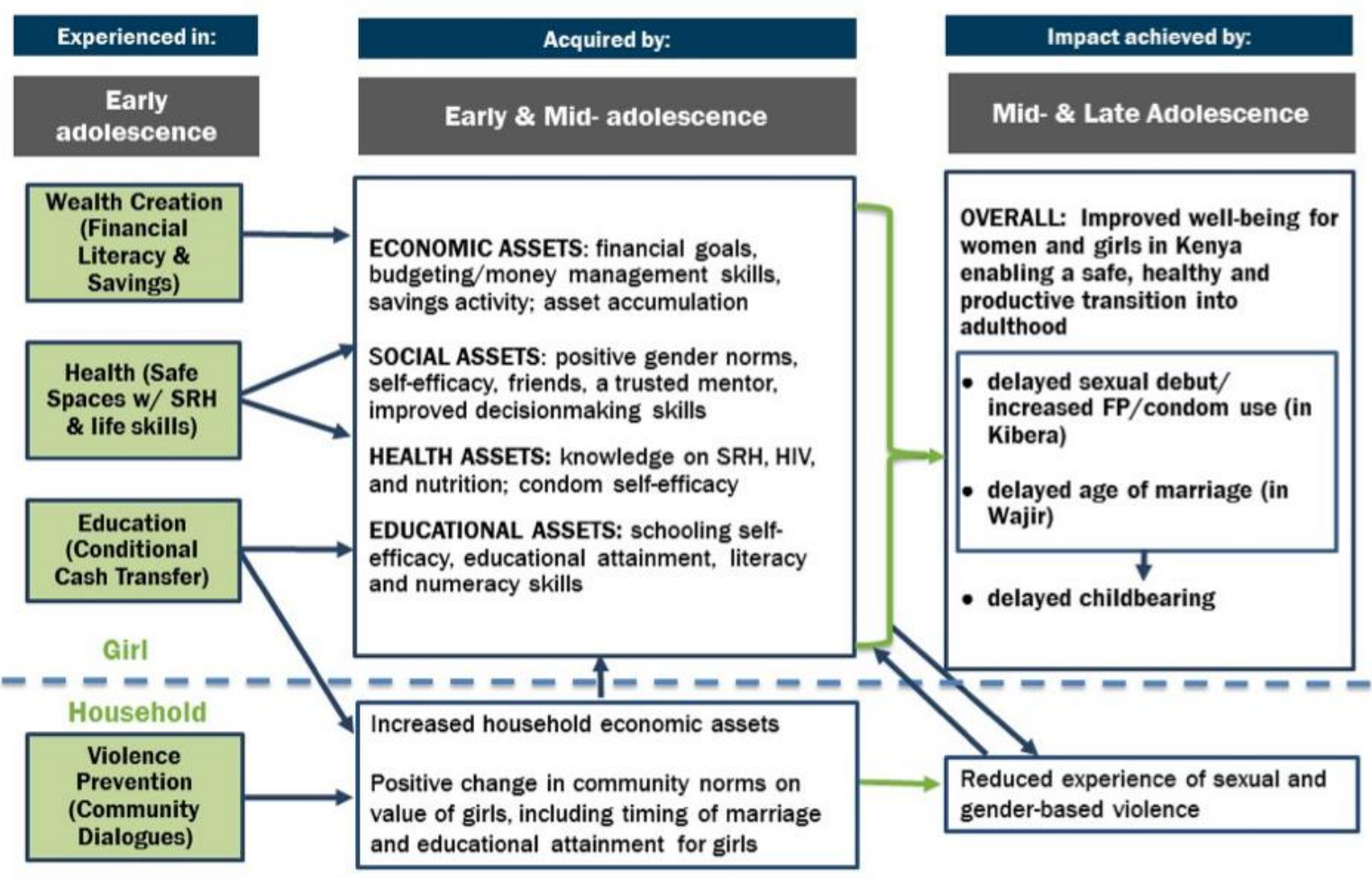




\section{AGI-K INTERVENTIONS}

As mentioned above, the goal of AGI-K is not to test single-sector interventions but to test multi-sectoral packages of interventions. AGI-K implemented the following packages:

1) Violence Prevention (V-only)

2) Violence Prevention + Education (VE)

3) Violence Prevention + Education + Health (VEH)

4) Violence Prevention + Education + Health + Wealth Creation (VEHW)

The selection of package combinations was based on three factors: 1) prioritizing what component effects were important to isolate; 2) generating evidence on new interventions and new combinations of interventions for which there are none; and 3) testing packages with varying implementation costs. The intervention design was guided by the theory of change and then each intervention component was adapted to take into account the local context.

\section{Sector-Specific Interventions (Austrian et al. 2016)}

\section{Violence Prevention}

The violence prevention intervention employed community-level dialogues and contracts. A committee was established in each community and included religious and community leaders, parents, teachers, and young men and women. The groups were taken through a facilitated process to identify key issues in the community that lead to the undervaluing of girls and the perpetuating of violence against girls and women. The committee then developed an action plan to implement a project meant to address and alleviate the issues facing girls in their community that they had identified. Each community conversation group was given a small fund with which to implement their project.

\section{Education}

The education intervention included a cash transfer conditioned on enrollment at the start of each term and regular attendance ${ }^{2}$ throughout the term. At the start of the intervention, all girls-whether in school or out of school-were eligible for the transfer upon school enrollment. The four components of the conditional transfer included:

1) fees, if applicable, to be paid directly to the school at the start of each term, ${ }^{3}$

2) a cash transfer paid to the head of the household twice per term, ${ }^{4}$

3) schooling kits given directly to girls at the start of each term containing sanitary towels, underpants, and basic school supplies; and

4) incentive paid directly to the school based on the number of girls enrolled in the cash transfer program. ${ }^{5}$

\section{Health}

The health intervention is based on the Population Council's safe spaces model (Austrian and Ghati 2010) in which girls met in groups once a week under the guidance of a female mentor from the community. Groups were segmented by age (11-12-year-olds in one group and 13-14-year-olds in the other) in Nairobi and by schooling status in Wajir. Group meetings included facilitated discussions using a health, life-skills, and nutrition curriculum, ${ }^{6}$ as well as

\footnotetext{
${ }^{2}$ Attendance was taken on a randomly selected day by external research assistants (RA) who visited the school and checked for the girl's presence. If a girl was absent on that day, the RA would return on a random day the following week. If a girl was absent on both days, she was deemed ineligible for the next payment.

${ }^{3}$ KES 700 ( US\$7) for primary school and KES 6,000 ( US\$60) for secondary school.

${ }^{4}$ The cash transfer payment amount in Kibera was KES 1,125 ( US\$11) and in Wajir the amount was KES 1,500 (approx. US\$15).

${ }^{5}$ The incentive payment was KES 500 ( US\$5) per girl.

${ }^{6}$ http://www.popcouncil.org/uploads/pdfs/2015PGY AGI-K HealthLifeCurriculum Wajir.pdf

http://www.popcouncil.org/uploads/pdfs/2015PGY_AGI-K_HealthLifeCurriculum_Kibera.pdf
} 
time for open discussion. In Wajir, the sessions used pre-recorded audio sessions to address wide variation in the capacity of the mentors. ${ }^{7}$

\section{Wealth Creation}

The wealth creation intervention included a financial education (FE) curriculum integrated into the safe spaces group meetings. ${ }^{8}$ In Wajir, girls received a home bank (piggy bank), and in Kibera, girls opened a girl-friendly savings account with the Kenya Post Office Savings Bank (Postbank). Girls in both sites received a small annual incentive of KES 300 ( US\$3) to allow them to put into practice the skills learned in the FE sessions.

\section{STUDY DESIGN/METHODOLOGY}

The main research questions explored vis-à-vis the endline survey were:

1) What were the effects of the AGI-K interventions on primary outcomes (childbearing, sexual debut, and marriage) two years after the program?

2) What were the effects of the AGI-K interventions on secondary outcomes (experience of violence, education, health assets, financial literacy, and savings) two years after the end of the program?

The research design for the study is a longitudinal RCT. The unit of randomization is different for the two sites: individual-level randomization in Kibera and cluster randomization in Wajir because of the differing geographies and population clustering. Each site is treated as a sub-study. For each sub-study, selected clusters/individuals were randomly assigned to one of the four arms after a household listing and baseline data collection were completed (see Figure 2). Assignment of clusters/individuals to study arms was conducted in the form of a public lottery to increase transparency. Comparisons are made relative to the V-only arm.

The primary target population was girls ages 11-14 who were residing within selected study sites at the time of the baseline survey and who were not in boarding school at the time of the listing and/or survey. Parents, guardians, and community members within these sites were targeted within the violence-prevention intervention.

\section{FIGURE 2. Randomized Controlled Trial Design and Timeline}

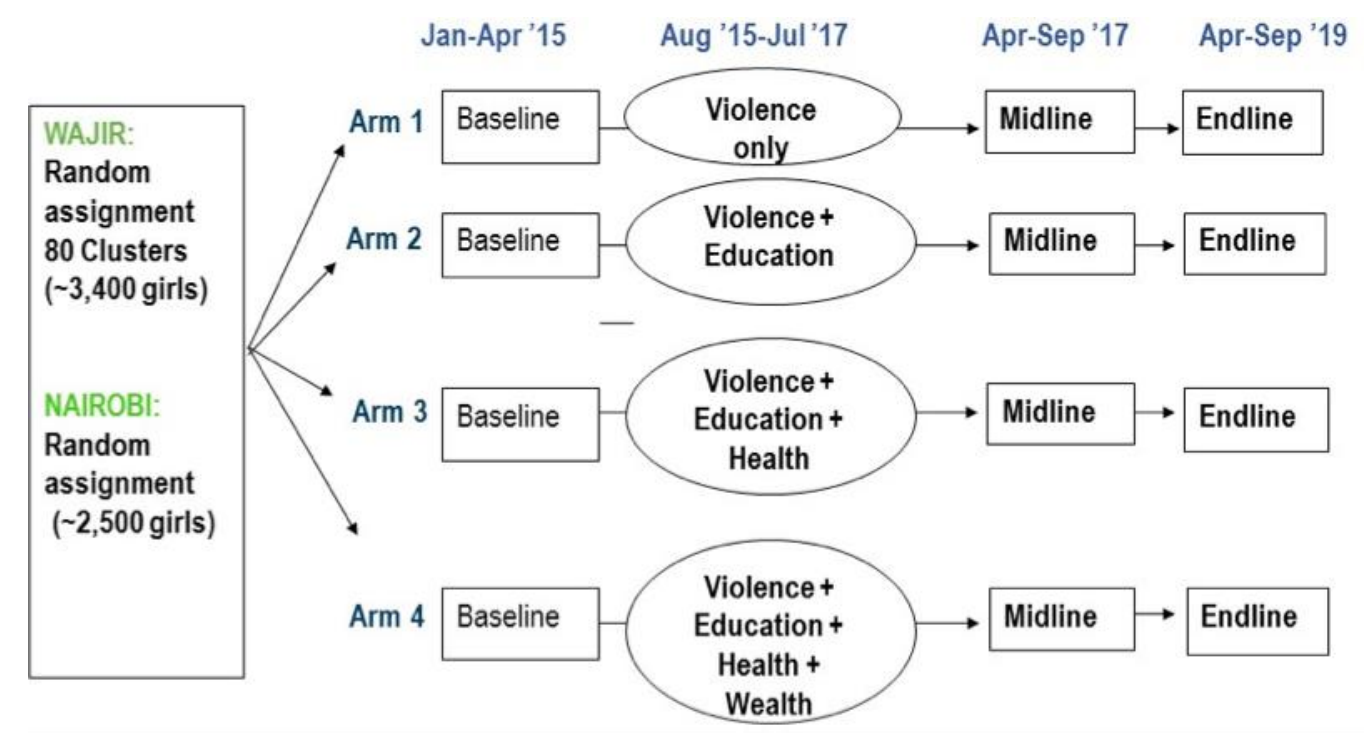

\footnotetext{
${ }^{7}$ http://www.popcouncil.org/uploads/pdfs/2018PGY_AGI-K_HLS-TrainingScriptWajir.pdf

8 http://www.popcouncil.org/uploads/pdfs/2015PGY_AGI-K_FinancialCurriculum_Wajir.pdf 


\section{Quantitative Data Collection}

The baseline survey was conducted between January and April 2015 in both study sites. The midline survey was conducted among the same cohort interviewed at baseline between April and July 2017 in Kibera and between July and September 2017 in Wajir and the endline survey between April and July 2019 in Kibera and July and September 2019 in Wajir (Austrian et al. 2016). Survey instruments were implemented by electronic data capture: Computer-Assisted Personal Interviewing (CAPI) on tablet computers. CAPI is a process of data capture in which the interviewer reads the question from a computer screen and enters the participant's response directly into a handheld or tablet device. For girls who moved outside the study area after baseline, teams were dispatched to locate and interview them at their current location of residence, after obtaining parental/guardian consent.

The key indicators included in the survey are found in Table 1.

TABLE 1. Key Indicators Per Sector

\section{Key Endline Indicators}

\section{Primary Outcomes}

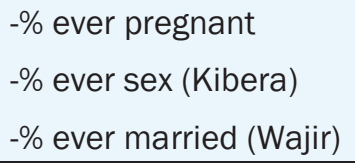

\begin{tabular}{|c|c|}
\hline \multicolumn{2}{|c|}{ Secondary Outcomes by Sector } \\
\hline Violence Prevention & $\begin{array}{l}\text {-experience of physical, emotional, or sexual violence by } \\
\text { a male in the past one year } \\
\text {-if reported experience of violence, sought help } \\
\text {-household-level norms on timing of girls' marriage } \\
\text {-household-level norms on girls' educational } \\
\text { attainment }\end{array}$ \\
\hline Education & $\begin{array}{l}\text {-primary school enrollment (Wajir only) } \\
\text {-\% who completed primary school (Kibera) } \\
\text {-\% currently enrolled in secondary school (Kibera) } \\
\text {-literacy score } \\
\text {-numeracy score }\end{array}$ \\
\hline Health & $\begin{array}{l}\text {-contraceptive method knowledge } \\
\text {-SRH knowledge (menstruation/STIs, HIV) } \\
\text {-general self-efficacy } \\
\text {-condom self-efficacy } \\
\text {-help-seeking self-efficacy } \\
\text {-social safety nets (trusted adults, trusted friends) }\end{array}$ \\
\hline Wealth Creation & $\begin{array}{l}\text {-financial literacy score } \\
\text {-savings prevalence } \\
\text {-household liquidity } \\
\text {-household wealth status }\end{array}$ \\
\hline
\end{tabular}




\section{Qualitative Data Collection}

The qualitative study population included girls who participated in the midline survey, as well as Community Conversations (CC) committee members (violence prevention-only arm) and key community stakeholders, including local government officials, religious leaders, school heads and teachers, safe spaces mentors, CC facilitators, and parents of beneficiary girls. In-depth interviews (IDIs) were completed in both project sites, with a total of 58 respondents from Kibera and 74 from Wajir (see Table 2). Qualitative data was collected in May 2018, almost one year after the completion of the intervention.

TABLE 2. Number of Qualitative Respondents by Site and Respondent Type

\begin{tabular}{|l|c|c|c|}
\hline \multicolumn{1}{|c|}{ Respondent Type } & Kibera & Wajir & Total Respondents \\
\hline Adolescent & 28 & $35^{*}$ & 24 \\
\hline Parent & 8 & 16 & 8 \\
\hline Safe Spaces Mentors & 4 & 4 & 8 \\
\hline CC Facilitators & 4 & 4 & 15 \\
\hline School Heads/Teachers & 8 & 7 & 14 \\
\hline Gatekeepers & 6 & 8 & 132 \\
\hline Total Respondents & 58 & 74 & \\
\hline
\end{tabular}

* Mini focus group discussions (FGDs) were conducted with 2-3 girls interviewed together as it was very challenging for the adolescent girls to engage in a one-on-one setting.

All adolescents, parents, and mentors were from the VEHW arm so as to allow for questions about all intervention components, and were purposively sampled based on key characteristics. In Kibera, adolescents were segmented on having a savings account or not and participation in program activities. In Wajir, girls were segmented by schooling status and participation in program activities. Adult respondents were sampled by gender, when applicable, and other characteristics including: public vs. private school and small vs. larger schools (for school heads and teachers), and level of capacity and performance (for mentors).

Key topics covered in the qualitative interviews were the perceived impacts of the four intervention components and areas where each could be improved. Respondents were probed to reflect on any change that may have occurred, either positive or negative, after the interventions ended. In addition, the topics of education, gender, and violence were explored, as well as the dynamics of sexual behavior in Kibera and the marriage process in Wajir.

Qualitative interviewers and moderators were trained over the course of two days by study investigators before conducting the IDIs and FGDs. In Kibera, interviews were conducted one-on-one. While it was the intention for interviews to be conducted one-on-one in Wajir, because of social and cultural norms in the region it was difficult for girls to feel comfortable and open up to the interviewer when alone. As a result, interviews in Wajir were conducted with two to three adolescent girls to ensure they were comfortable in the interview setting. Prior to initiating group discussions, adolescent and adult respondents were reminded of the importance of ensuring confidentiality. All IDIs and FGDs in Kibera and Wajir were completed by May 2018.

Interviewers and focus group moderators followed semi-structured interview guides that provided main questions and additional probes to elicit in-depth responses. The guides were translated to Swahili (for Kibera) and Somali (for Wajir), pilot-tested, and revised based on interviewer feedback prior to initiation of data collection.

A brief socio-demographic form was completed for each IDI and FGD respondent at the time of the interview or discussion. The form captured information on the study site, study arm, village of residence, respondent's age, highest level of education, religion, occupation, marital status, and living arrangement (adolescents only). 


\section{Ethics}

Before administering the survey or qualitative interview, informed consent was obtained from parents/guardians of girls and assent from the girls themselves. Parental consent was not required from emancipated minors. ${ }^{9}$ To the extent possible, interviews were conducted in an area with visual and auditory privacy. For girls who moved outside the study area between baseline and endline, teams were dispatched to locate and interview them at their current location of residence, after obtaining parental/guardian consent. The study was reviewed and approved for compliance by the Population Council Institutional Review Board (IRB) and the AMREF Ethics \& Scientific Review Committee. In addition, research permits were obtained from the National Council on Science, Technology and Innovation in Kenya.

\section{Analysis}

\section{Quantitative Analysis}

Logistic regressions were estimated to assess differential attrition across arms, and linear regressions were estimated to assess balance across study arms at baseline among the sample followed up at midline and at endline.

To estimate the impact of the education, health, and wealth interventions, each study arm with combinations of these interventions was compared to the V-only arm. An intent to treat (ITT) approach was followed. ITT was defined as girls randomized to a specific study arm in Kibera, and as girls living in a village randomized to a specific study arm in Wajir, irrespective of whether girls had actually participated in the intervention. Linear regressions were estimated to obtain coefficients representing the differences between each of the study arms and the V-only arm attributable to the interventions. For outcomes that were measured both at midline and endline, coefficients were obtained for both time periods and compared to assess changes in the impact of the interventions across time.

To assess the impact of adding the health intervention to the education intervention, comparisons across the VE arm and the VEH arm were conducted. To assess the impact of adding the wealth intervention to the education and health interventions, comparisons across the VEH arm and VEHW arm as well as across the VE arm and the VEHW arm were conducted.

Additional analysis including interaction terms with baseline characteristics was conducted to test whether the interventions had differential impacts for the following subgroups of girls:

- Older girls (ages 13 and older at baseline) compared to younger girls (ages 12 and younger at baseline)

- Girls from the poorest wealth quintile at baseline compared to girls from less poor backgrounds at baseline

- Girls not living with a biological parent at baseline compared to girls living with at least one of their biological parents at baseline

- Kibera: Girls who had completed grade 7 at baseline compared to girls who had not yet completed grade 7 at baseline

- Wajir: Girls who were out of school at baseline compared to girls who were in school at baseline

All regressions controlled for age at baseline and, when available, the outcome measured at baseline. As randomization in Wajir was stratified by district (Wajir East, Wajir South, and Wajir West), regressions for Wajir also controlled for district. Regressions for Kibera were estimated with robust standard errors, and regressions for Wajir were estimated with robust standard errors accounting for clustering at the village level. All statistical analysis was conducted using Stata 15.1.

\section{Qualitative Analysis}

All interviews and focus groups were tape-recorded with participant permission and transcribed verbatim. All tape recordings were first transcribed in the language of the interview, a mix of English and Swahili in Nairobi and Somali

\footnotetext{
${ }^{9}$ Emancipated minors were defined as married girls, mothers, or girls who were heading their own household.
} 
in Wajir, and subsequently translated into English. Following translation, all transcripts were validated and reviewed for quality assurance by a second transcriber prior to being coded. No personal identifying information, other than the assigned participant identification numbers, were included in the transcriptions.

Following transcription, all IDI and FGD transcripts were coded for emerging themes by a qualitative data analyst and a trained research assistant using ATLAS.ti software. The analysis involved first developing a coding dictionary based loosely on the structure of the interview guides. This coding dictionary was developed by the analyst trained in identifying key concepts/codes that are useful for summarizing the results and subsequently reviewed by project research staff. The coding dictionary was then input into ATLAS.ti and relevant "codes" were attached to the corresponding concepts mentioned within each transcript.

In the beginning stages of coding, a preselected number of transcripts were double-coded to ensure mutual understanding in the interpretation and usage of the codes across analysts. Following this process, three IDI transcripts were selected to run tests of intercoder agreement (ICA) using the ICA mode in ATLAS.ti. Through the ICA mode, double-coded transcripts were uploaded and merged into a single file, to which Krippendorff's c- $\alpha$-binary coefficient could be obtained for randomly chosen, preselected codes, as well as for all of the codes together. A coefficient of 0.70 or greater was considered acceptable and indicated sufficient intercoder reliability, defined here as the extent to which independent coders evaluate a block of text and reach the same conclusion (i.e., to apply the same code). A coefficient of less than 0.70 resulted in side-by-side comparison, clarification on, possible revision to the code definition, and reconciliation before any additional transcripts were completed.

After all transcript and focus groups transcripts had been coded, output for all relevant codes was generated and used for analysis and the write-up of the report. Word-for-word quotations are presented to illustrate the key issues and themes that emerged.

\section{Benefits valuation methodolog $y^{10}$}

The aim of the benefits valuation was to put a value on the benefits of the AGI-K program, using endline quantitative results, to estimate what the program achieved in monetary terms. While this is not a full cost benefit analysis due to the methodological limitations, it does allow for use of the endline data quantitatively to understand what type of monetary benefit the program can offer if scaled up.

This analysis uses the calculated, statistically significant reductions in pregnancy in the intervention groups (relative to the control group) for Kibera and Wajir. From these endline findings, we quantified the impact of the program in terms of avoided marriages and births in the AGI-K sample before the age of 18 , and how that in turn led to reductions in total fertility, reductions in under 5 deaths and perinatal conditions, reductions in nutritional deficiencies, reductions in intimate partner violence, reductions in maternal conditions and improvements in labor force activity due to better education. In converting these findings into monetary values, key assumptions were taken from World Bank empirical evidence, the Nairobi Cross Sectional Slum Survey, WHO Kenya specific DALY database on the burden diseases, and the 2014 Kenya Demographic and Health Survey. The quantitative data is valued using assumptions about Gross Domestic Product (GDP) per capita and the statistical value of life.

In a benefit valuation, there are two possible types of benefits:

Private benefits-those incurred by individual girls and their households-i.e., avoidance or reductions of the following due to delaying marriage and childbirth:

- $\quad$ under $5 s$ mortality due to health complications of early childbirth,

- $\quad$ perinatal conditions ${ }^{11}$

\footnotetext{
${ }^{10} \mathrm{~A}$ full detailed methodology is provided in the more detailed, standalone benefits valuation report.

${ }^{11}$ Prematurity and low birthweight, birth asphyxia and birth trauma, neonatal infections, and other conditions.
} 
- $\quad$ child nutritional deficiencies ${ }^{12}$

- intimate partner violence

- maternal conditions ${ }^{13}$

- $\quad$ health-care costs due to better health

- labor-force improvements for girls due to delayed marriage and childbirth.

Public benefits-those incurred by society at large-e.g., the demographic dividend, poverty reduction and economic growth at large due to reduced total fertility rate.

This estimation focuses on the above-mentioned private household benefits.

\section{Response Rates}

Overall endline response rates were high with $89 \%(n=2,078)$ of the Kibera baseline sample being interviewed at endline and $90 \%(n=2,042)$ of the Wajir sample (see Table 3). Nineteen percent of the original Kibera sample was tracked and interviewed outside of Nairobi City County. All baseline respondents, regardless of whether or not they were interviewed at midline, were attempted in the endline sample.

TABLE 3. Interviews Completed (\% of Baseline Interviewed) by Arm, by Site

\begin{tabular}{|l|c|c|c|c|c|c|c|c|}
\hline & \multicolumn{5}{|c|}{ Kibera } & \multicolumn{4}{c|}{ Wajir } \\
\hline Arm & V-Only & VE & VEH & VEHW & V-Only & VE & VEH & VEHW \\
\hline Baseline & 597 & 588 & 609 & 590 & 506 & 553 & 537 & 551 \\
\hline \multirow{2}{*}{ Midline } & 506 & 556 & 569 & 550 & 448 & 472 & 491 & 501 \\
& $(85 \%)$ & $(95 \%)$ & $(93 \%)$ & $(93 \%)$ & $(89 \%)$ & $(85 \%)$ & $(91 \%)$ & $(91 \%)$ \\
\hline \multirow{2}{*}{ Endline } & 484 & 528 & 534 & 532 & 470 & 516 & 524 & 532 \\
& $(81 \%)$ & $(90 \%)$ & $(88 \%)$ & $(87 \%)$ & $(93 \%)$ & $(93 \%)$ & $(98 \%)$ & $(97 \%)$ \\
\hline
\end{tabular}

\section{Program Uptake}

Overall, participation in the cash transfer was high with only $7.5 \%$ of eligible households in Kibera and $11.5 \%$ of eligible girls in Wajir never receiving a cash transfer over the two-year intervention period. The mean number of transfers received (out of a total possible of 12) was 9.5 and 9 in Kibera and Wajir, respectively. Eighty-two percent of girls in the VEHW arm in Kibera opened savings accounts with Postbank ${ }^{14}$ and $79 \%$ of girls in the VEHW arm in Wajir received a home bank. In Kibera, the mean number of sessions attended was 36 and about $6 \%$ of girls in the VEH and VEHW arms never attended their safe spaces group and $48 \%$ participated in the mean or higher number of sessions. In Wajir, the mean was 33 sessions and about $8 \%$ of eligible girls never attended a session and $47 \%$ participated in the mean or higher number of sessions. For a more detailed description of the safe spaces attendance data, see the AGI-K midline report. ${ }^{15}$

\footnotetext{
12 Protein energy malnutrition, iodine deficiency, vitamin A deficiency, Iron deficiency anemia.

${ }^{13} \mathrm{~A}$ maternal condition is any health condition in the mother that may cause pregnancy complications. Common maternal conditions include: multiple gestation, gestational diabetes, Isoimmunization (blood type differences between the mother and baby).

${ }^{14}$ Cash transfer payments were made into an Equity Bank account held by the girl's mother, father, or guardian. Girls in the VEHW arm opened their own savings accounts at Postbank, irrespective of the Equity Bank accounts.

${ }^{15}$ https://www.popcouncil.org/uploads/pdfs/2018PGY_AGI-K_MidlineReport.pdf
} 


\section{Endline Results}

This AGI-K endline survey report focuses on the impact of the intervention on the primary long-term study outcomes, and on key indicators in each of the four sectors: education, health, wealth creation, and violence. The results presented compare the violence prevention-only arm to the other three arms.

Results for Kibera and Wajir are presented separately. The two locations differ greatly with respect to economic opportunities, geography, religion, and culture, so a direct comparison is not possible. However, some of the differences in impact between the two sites provide further insights into what did and did not have an effect in different contexts.

\section{KIBERA}

\section{Sexual Debut and Pregnancy:}

The hypothesis was that the change that occurred at midline in education, social, health, and economic assets would, via delayed sexual debut and/or use of contraceptives, lead to delayed pregnancy. Overall, among girls who were 13 years and older at baseline,${ }^{16}$ girls in the VE, VEH, and VEHW arms were significantly less likely to have initiated sexual activity ( $\sim 24 \%$ as compared to $33 \%$ in the V-only arm) (see Figure 3 ). Furthermore, girls 13 years and older in the VE and VEHW arms were almost half as likely to have given birth as compared to the V-only arm (6\% v. $11 \%)$ for all girls, and that difference is significant when not limiting by age. There was no effect on having given birth for the VEH arm. As there was no increase in the use of family planning, including condoms, the delay in pregnancy is likely due to the delays in sexual debut.

FIGURE 3. Impacts on Sex and Fertility, Kibera
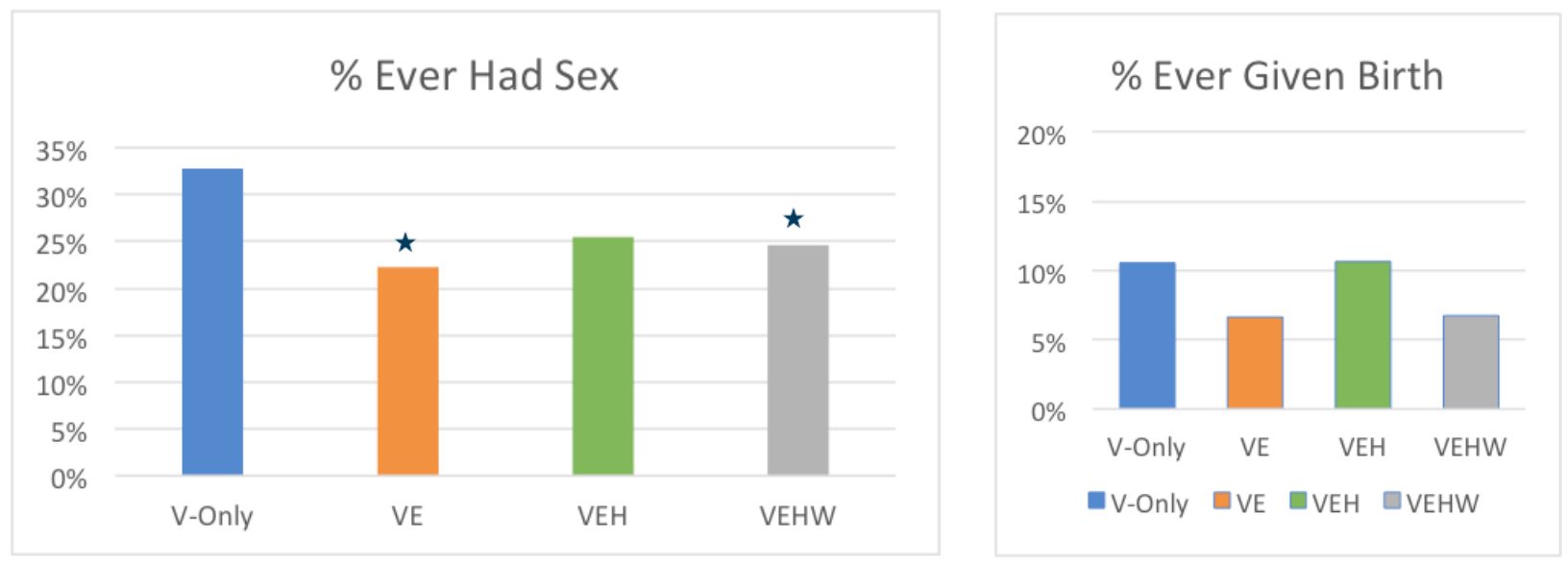

NOTE: Includes only those aged 13 years and above at baseline. * $p<0.05$.

\section{Education:}

At the end of the two-year intervention (midline), among girls who had completed class 6 by baseline, and could therefore complete primary school and transition to secondary school during the course of the intervention, girls who had received the cash transfer were more likely to have both completed primary school and transitioned to secondary school. Two years after the intervention ended (endline), girls who had received the cash transfer (VE,

\footnotetext{
${ }^{16}$ We look at sexual activity and childbearing for all girls, as well as those who were 13 years and older at baseline, as the latter group would have been 17-19 at endline and more likely to have transitioned into sexual activity.
} 
VEH, and VEHW) were significantly more likely to have completed primary school ( $92 \%$ v. $88 \%)$ and be enrolled in secondary school ( $88 \%$ v. $82 \%$ ) than girls in the V-only arm (see Figure 4). There were also no meaningful differences between the cash transfer arms (VE, VEH, and VEHW) and the control arm in literacy and numeracy scores at endline.

\section{FIGURE 4. Impacts on Education, Kibera}

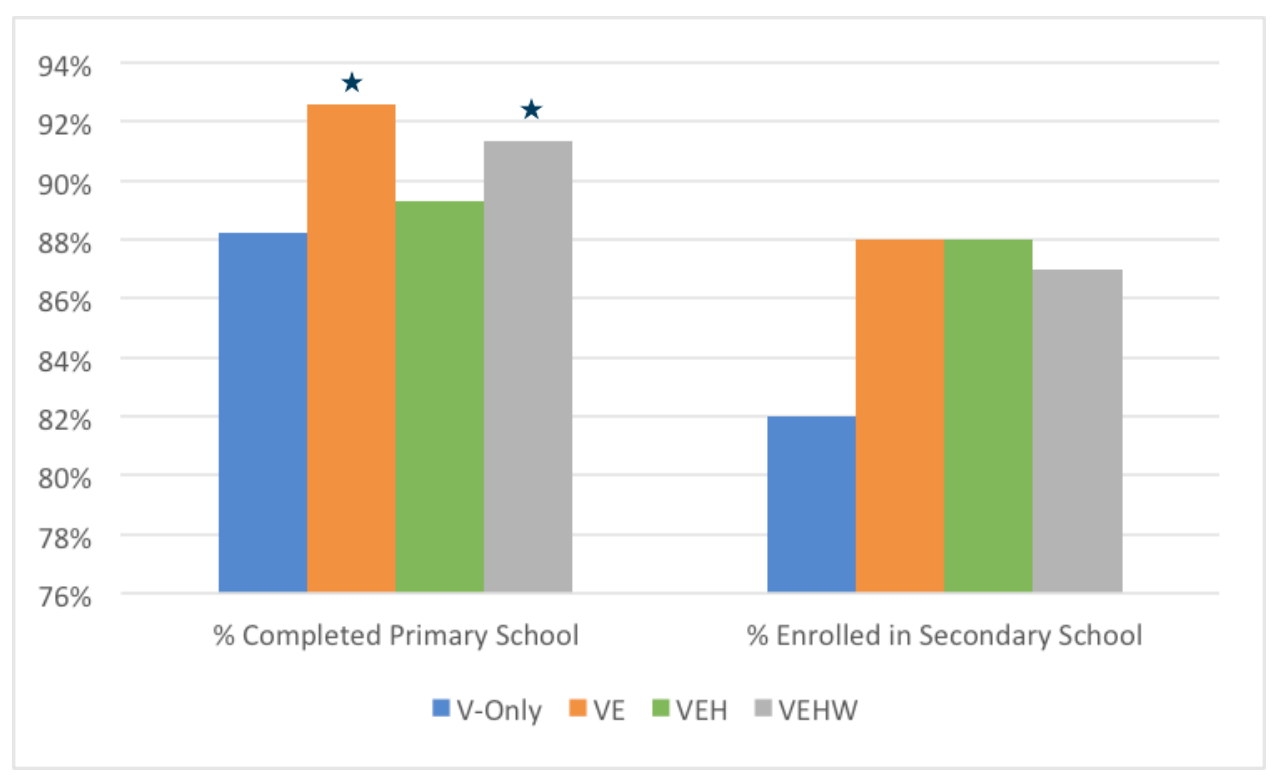

NOTE: For secondary school enrollment, the difference relative to the control is significant for the VE, VEH, and VEHW arms when the bottom household wealth quintile is excluded. * $p<0.05$.

There were additional benefits gained from the cash transfers that were not evaluated in the quantitative analysis but were highlighted in the qualitative analysis. Respondents reported that the cash transfers increased attendance at school and girls in Kibera were not sent home due to lack of school fee payment. Families benefited from the household transfer and were able to buy food and clothes for the entire family. The program also impacted the girls and girls' parents' goals for their education. Girls stated they had the goal of attending university and their motivation for studying increased.

"I liked it because my parents didn't have jobs, so when the money was sent to them they would buy food and other household necessities...and also the payment of school fees." Adolescent girl, Kibera

"I never missed going to school after they started paying my school fees...previously I might be in school one day, when sent home for fees my parents may not have the money so had to stay at home while they look for the money. When they get it they would give it to me and I would go back to school." Adolescent girl, Kibera

Parents reported that they used the cash transfer to purchase girls' school supplies and uniforms as well as other goods. It was also reported that the cash transfers helped a few parents move their children to more expensive, better-quality schools or boarding schools, however after the program ended, some girls switched back to lowerquality schools because they could not afford to pay the entire school fee.

\section{Health:}

At midline, girls in the VEH and VEHW arms had increased knowledge on contraception, menstruation, STIs, and HIV. In addition, girls in the VEH and VEHW arms had strong social networks by way of female friends and female adult mentors. While there was no effect on general self-efficacy, there was a positive impact on condom selfefficacy and help-seeking self-efficacy. Finally, there was no impact on gender norms or acceptability of IPV.

At endline, while the VEH and VEHW arms still had higher knowledge of contraceptives as compared to the V-only arm, the VE arm also "caught up" to the VEH and VEHW arms on contraceptive knowledge. On other health-related 
indicators-including other dimensions of knowledge, social networks, self-efficacy, and gender norms-while there were not declines for the VEH and VEHW arms, the V-only and VE arms "caught up" and therefore there was no longer a significant difference relative to the V-only arm.

Most girls interviewed said they enjoyed the safe spaces meetings and had a positive relationship with the mentor. Both adolescents and parents from Kibera reported satisfaction with the safe spaces meetings and curriculum. Many girls reported to have gained important knowledge from the meetings, for example how to maintain hygiene and cleanliness, protect themselves from boys and against violence, eat a balanced diet, and delay sex. In addition they reported to have shared this knowledge with other girls outside of their groups.

"Before, when the periods came I didn't know what to do. The blood stained my uniform while I was in school and I would feel embarrassed. ... Now I can guide and counsel my friends." Adolescent girl, Kibera

Girls reported that the safe spaces built their self-esteem and confidence, motivated them to enhance their educational goals and claim self-worth. Parents reported that the girls adopted positive changes in behavior that led to improved relationships with them, although some girls reported that it was challenging to maintain all of the positive behavior change when the program ended.

"Like you have that confidence to do anything. You can approach anyone with confidence." Adolescent girl, Kibera

"I have remained with how I relate with people outside there. We were taught on assertiveness there and it has helped me up to now." Adolescent girl, Kibera

"Learning about being free to speak. If someone wrongs me, I am free to tell them that it is like this or that. In the past I wasn't free to talk to someone like that." Adolescent girl, Kibera

However, many respondents reported that they were not able to attend the safe spaces on a regular basis mainly because of conflicting weekend school sessions and attending boarding school. Most girls reported that the safe space meetings did not continue beyond the end of the program. These observations may partly explain the endline impact of this component of the intervention across the arms.

“When [girl's name] got to class 8 , she could not attend the meetings because she would go to school even on Sundays. I explained to her that [girl's name] would not be coming for the meetings because she had to go for tuition, and they would be beaten up if they didn't go." Mother, Kibera

\section{Wealth:}

At midline, girls in the VEHW arm had increased financial literacy, savings frequency, and savings amount relative to the other arms that did not receive the wealth creation intervention. At endline, girls in the VEHW arm still had significantly higher scores on the financial literacy scale relative to the other three arms, as well as were more likely to save (56\% v. 46\%) (see Figure 5), although the effect size was not as large as at midline.

FIGURE 5. Impacts on Financial Literacy and Savings, Kibera
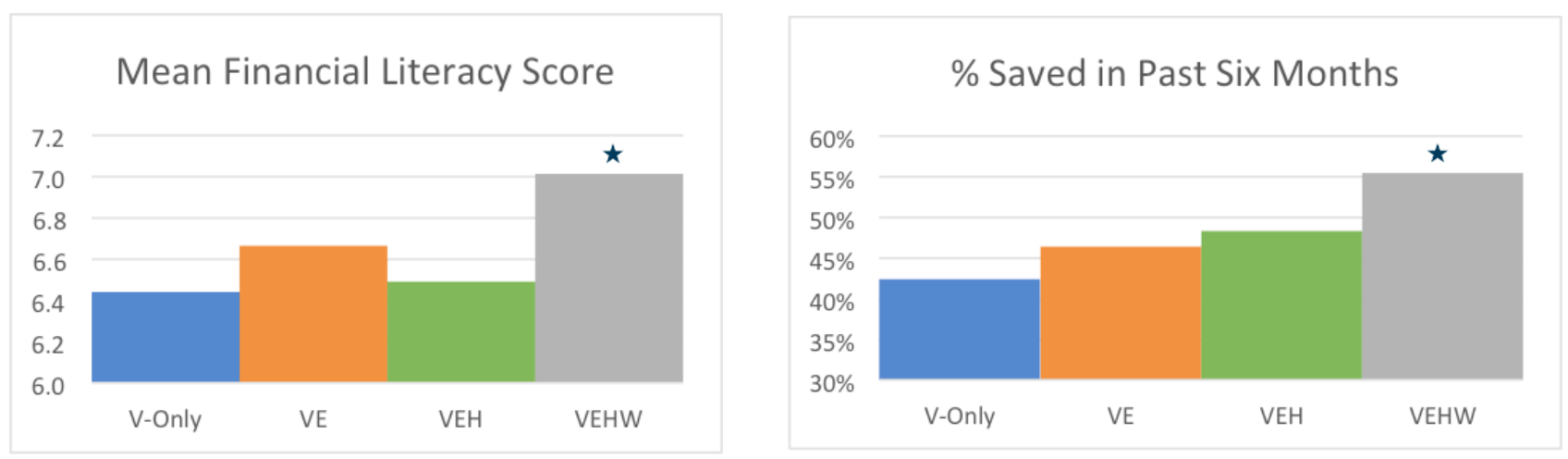
These findings were supported by the qualitative data as respondents reported that girls practiced the lesson of saving to buy items they need and avoid impulse buying such as snacks. In addition, girls learned to deposit even small amounts as often as possible and parents would contribute to their savings when they could. Parents were reported to also give girls money to deposit into their savings account. Many girls continued to use their savings accounts and deposit often even after the end of the intervention.

"I deposit like after [every] two months, but I have never withdrawn... I still use that [same account]." Adolescent girl, Kibera

"When I opened that account, it's the one that I am still using to save. Even if the program has ended... it's still helping me now." Adolescent girl, Kibera

At the household level, households in the VEHW arm still had higher liquidity and were in a higher wealth quintile relative to the V-only arm at endline (see Figure 6).

\section{FIGURE 6. Impacts on Household Economic Status, Kibera}

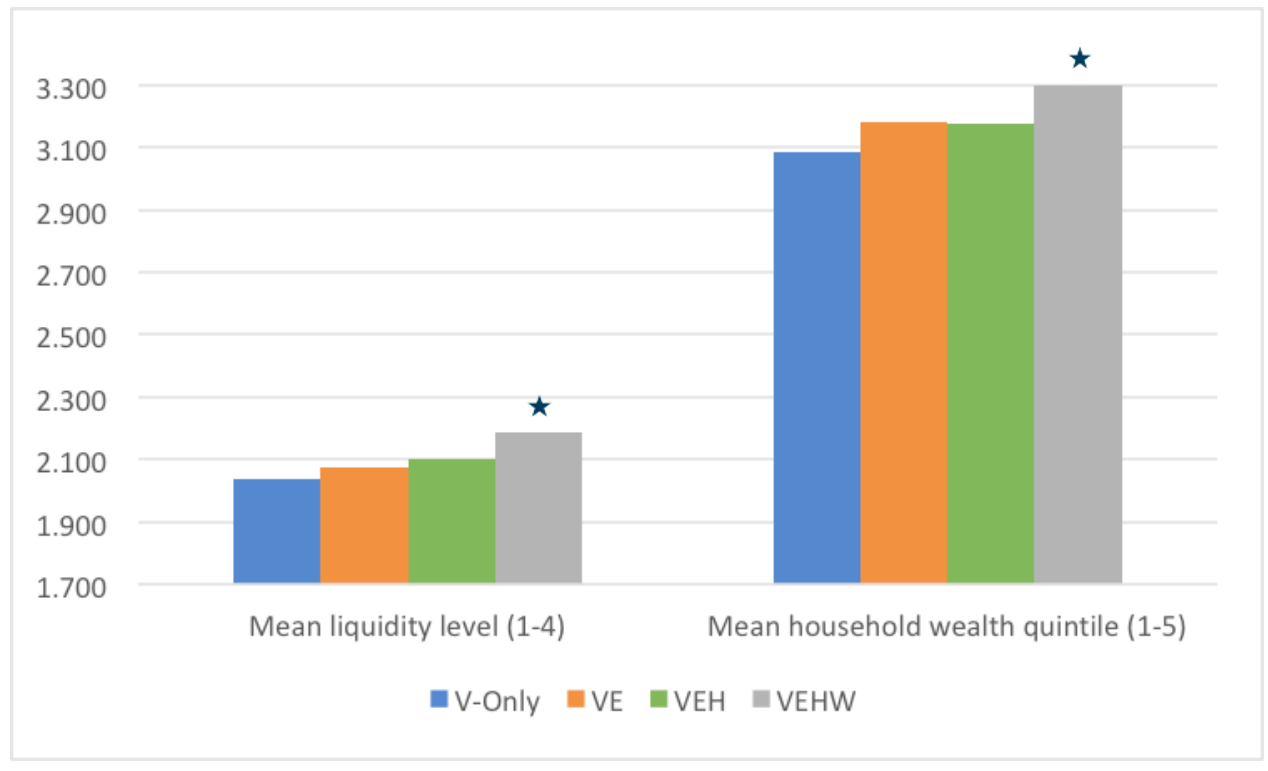

$* p<0.05$

\section{Violence Prevention:}

At midline the girls in the VE, VEH, and VEHW arms reported experiencing less violence by a male in the past year as compared to the girls in the V-only arm. However, by endline, that difference no longer existed. There was also still no difference between arms vis-à-vis help-seeking behaviors for those who had experienced violence. In addition, there was no difference in norms across arms for girls completing secondary school or marrying after the age of 22 , as the household ascribed to positive gender norms on these measures from baseline.

The qualitative findings elude to potential barriers that may have resulted in the community dialogues and contracts strategy being less effective. Respondents reported an imbalance of gender representation in the meetings with most attendees being female and minimal representation from religious leaders. Attendees also missed many meeting because of other commitments such as work and travel, compounded by poor planning by the committee members and implementation team. Members also reported that the lack of incentives or refreshments during the meetings resulted in decreased commitment and decreased participation.

"So in future if you need to meet the parents, you should send a text message via phone. For example, if you need us on Saturday, send us the message by Friday or Thursday so I can plan my work and make time...." Father, Kibera 


\section{WAJIR}

\section{Marriage and pregnancy:}

The hypothesis was that the effects seen at midline on girls' educational attainment, as well as social, health, and economic assets-together with effects at the household and community levels-would translate into delayed marriage, and hence delayed childbearing. When looking at the full sample, there is no effect on marriage ( $14 \% \mathrm{v}$. $12 \%$ ) and childbearing ( $10 \%$ v. $7 \%$ ) between the girls in the V-only arm as compared to girls in the VE, VEH, and VEHW arms. However, when looking at the girls who were out of school at baseline, ${ }^{17}$ which made up $29 \%$ of the sample, there were large effects on both marriage and childbearing with $50 \%$ of girls in the V-only arm being married as compared to $30 \%$ of the girls who were in one of the cash transfer arms (see Figure 7). Furthermore, $34 \%$ of girls in the V-only arm had ever been pregnant at endline as compared to $17 \%$ in the cash transfer arms.

\section{FIGURE 7. Impacts on Marriage and Fertility Among Girls Out of School at Baseline, Wajir}

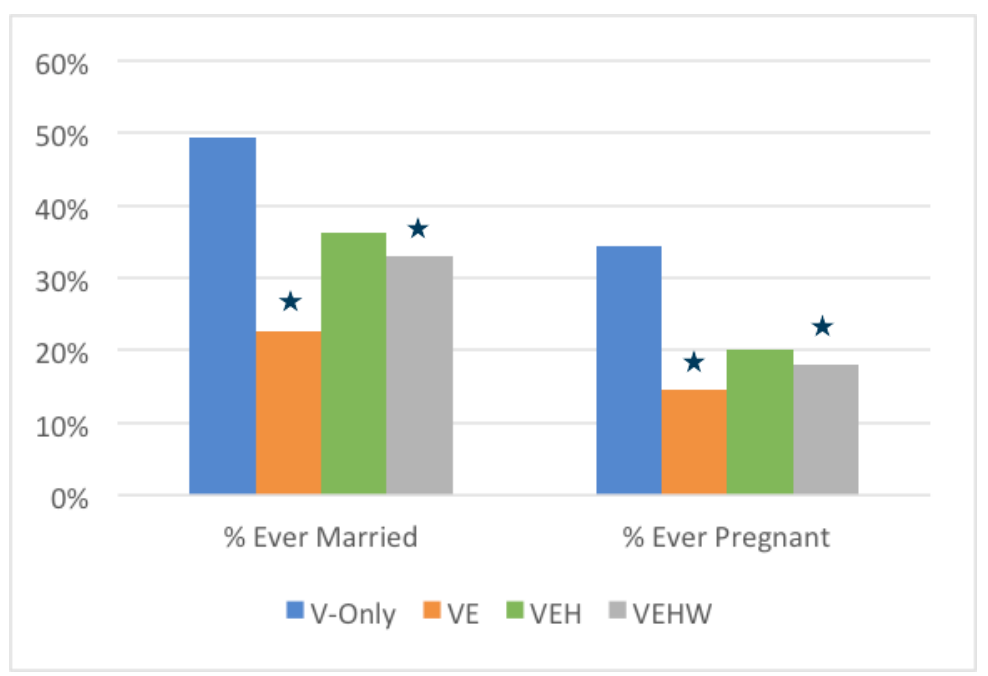

$* p<0.05$.

\section{Education:}

At the end of the two-year intervention (midline), there were significant improvements in primary school enrollment for girls in all three cash transfer arms, as well as in numeracy skills. Two years after the intervention ended (endline), there were sustained effects on having ever attended school for the whole sample, and the effects were significant for the VE and VEHW arms. However, similar to the marriage and pregnancy results, the effects on primary school enrollment were largest for girls who were out of school at baseline, with only $16 \%$ of girls in the V-only arm enrolled at endline as compared to $45 \%$ of girls in the cash transfer arms. In addition, there were substantial improvements in literacy and numeracy skills for these girls (see Figure 8 ).

\section{FIGURE 8. Impacts on Education and Learning Skills Among Girls Out of School at Baseline, Wajir}
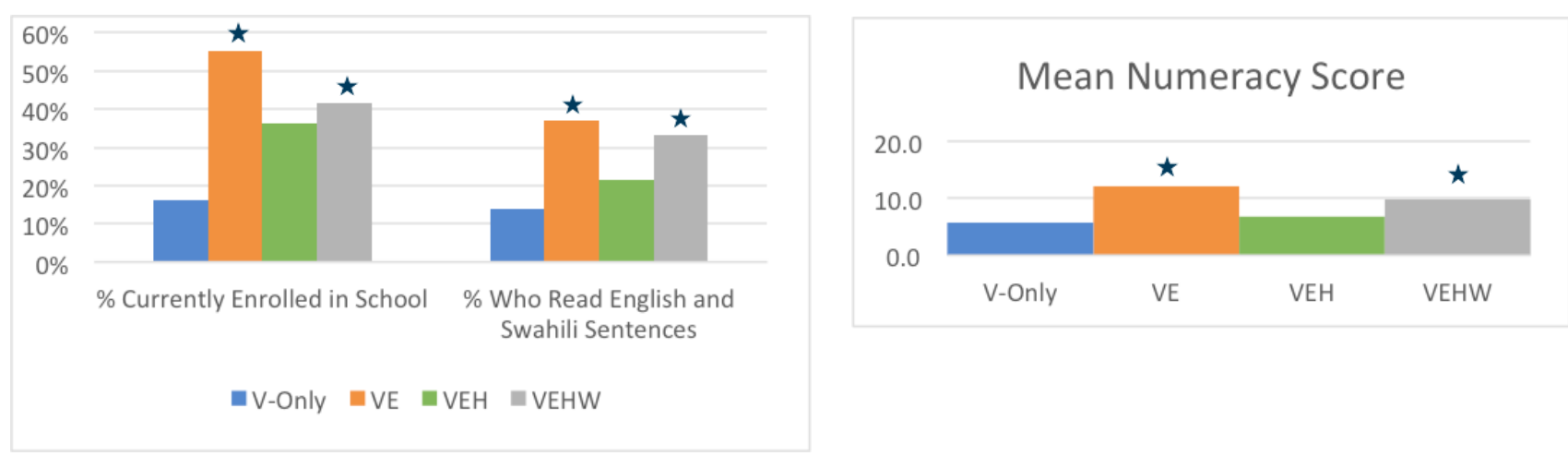

${ }^{17}$ Although the proportions out of school at baseline vary by arm, they are a result of the randomized process so we have no reason to think the selectivity of these girls is systematically different across arms. In addition, while the proportion out of school at baseline varied by arm, when controlling for the same covariates as in the attrition models, arms are not statistically significantly associated with the likelihood of being out of school at baseline. 
Some respondents in the qualitative interviews reported girls having improved motivation for continuing their education, talking more generally about furthering their education as a result of the AGI-K program but not necessarily going to university. Respondents also stated that the girls in the program had adequate sanitary towels for menstruation due to the school kits.

"What I like most is the sanitary towels that was given to the girls because you won't know when she will get her menses, but now we are at ease because they have been taught how to handle such cases and how to use the sanitary pads properly." Mother, Wajir

\section{Health:}

At midline, while there was no effect on SRH knowledge, there were improvements in general self-efficacy and help-seeking self-efficacy within the VEHW arm. At endline, there were no differences between arms on any of the intermediate health outcomes as levels largely stayed the same or the V-only girls "caught up," however among the girls who were out of school at baseline, there were improvements in having positive gender norms for girls in the VE and VEH arms, an effect that was not observed at the end of the intervention (see Figure 9).

\section{FIGURE 9. Impacts on Equitable Gender Norms Among Girls Out of School at Baseline, Wajir}

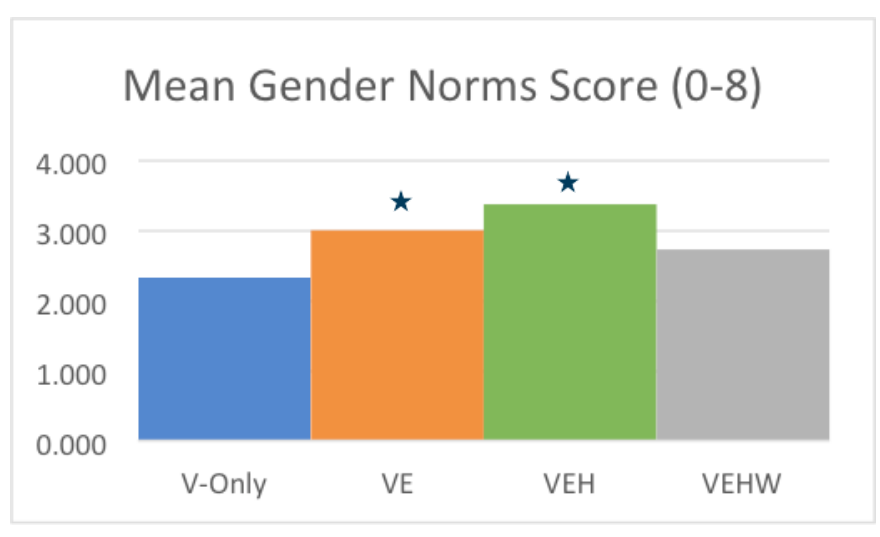

$* p<0.05$

Similar to Kibera, most girls reported satisfaction with the safe spaces meetings and curriculum, enjoyed the safe spaces meetings, and had a positive relationship with the mentor. Many girls reported gaining important knowledge about menstruation, hygiene, and nutrition, and in sharing this gained knowledge with their peers outside the groups.

"What they liked most is the topic on hygiene maintenance where they were taught how to use the sanitary towels... I used to teach them how to cook and tell them to always wash their hands before and after every meal, and they enjoyed it a lot." Mentor, Wajir

"We were told to cook different foods... protein like beans, carbohydrates, and vitamins." Girl, Wajir

Many girls and mentors reported girls not being able to attend several meetings mainly because of having to watch over family cattle, and lack of parent understanding, support, or encouragement. Respondents also talked about how the meeting schedule conflicted with important religious services and teachings.

"[Girls] were more likely to miss because their parents tell them to do household responsibilities and they also look after the animals, specially the first-born girls." Mentor, Wajir

Although parents and gatekeepers in Wajir reported satisfaction with many components of the curriculum, such as topics related to menstrual hygiene and management and savings, the qualitative findings also highlight the many 
misconceptions and concerns that still exist concerning some of the topics covered in the sexual and reproductive health curriculum. This may explain the lack of effect on the SRH knowledge measures.

"The community was divided on this (safe spaces groups). Obviously the educated ones welcomed the program, while there were those who didn't welcome the program even though the ones who didn't welcome the program were few." Community Gate Keeper, Wajir

"There were topics that were not ideal to this context they were being taught." Father, Wajir

\section{Wealth Creation:}

At midline, girls in the VEHW arm had higher financial literacy and were more likely to have saved as compared to the other three arms. At endline, there was no longer a significant difference in financial literacy. Despite a large drop in savings behavior between midline and endline (42\% to $9 \%$ ) and generally low levels of saving, girls in the VEHW arm were still more than four times more likely to have saved in the past six months as compared to the other three arms (9\% v. $2 \%)$.

As at midline, there were no differences in household economic status between arms.

In the qualitative interviews, girls in Wajir did not discuss challenges with the savings activities. One issue that came up was that girls who were not in school or who did not attend the safe spaces meetings did not receive the home banks or incentives. Some girls reported that they were able to save enough money to help their families during tough times.

"I have used my savings to buy clothes and also shared some of the money with my mother." Adolescent girl, Wajir

"I was a member of a merry-go-round (saving's group) and we managed to raise some good amount which we divided amongst ourselves. My share was KES4,500 which I spent on a bed for my mom." Adolescent girl, Wajir

Several respondents reported that families in Wajir struggled when accessing the cash transfers. If there was no bank nearby (or if there were issues with the local bank), parents would have to travel far distances to retrieve the money. This cost the family money and time, and the withdrawal fee also cut into the total they received after travel and accommodation to retrieve the money was subtracted. This may partly explain why the cash transfers had no impact on economic status between the arms.

"There is only one person who does the withdrawals and sometimes the machine may break down. If one person withdraws the other person may not be able to access it, so we have to go Wajir town to get the money. After such an incident happened to me I actually had to borrow money from my neighbor in order to go to Wajir town and collect the money. Remember the money is only 1,500 shillings, part of which will be used on transport to get back home; whatever remains is so little." Mother, Wajir

The cash transfers to the households were used to buy items for the girls and food for the family, also explaining why it did not lead to accumulated wealth.

"It helped the parents...they are poor pastoral families and the money they were getting every month has helped improve their living standards." Mentor, Wajir

\section{Violence:}

At midline, while there was no effect on the reporting of violence, there were improvements in gender norms at the household level vis-à-vis timing of girls' marriage and educational attainment. At endline, there was still no difference in the reporting of violence, although overall reporting of violence remained very low. There was also no 
longer any difference in household gender norms, although across the four arms there was very positive gender norms with over $95 \%$ of households reporting that girls should complete secondary education and marry after the age of 18.

Similar to Kibera, respondents from the qualitative interviews mentioned a lack of commitment from community members to attend the violence prevention intervention because of a lack of monetary incentives.

"If were given maybe some refreshments and sitting allowances or even books it could have been better because some of the parents miss a lot of meetings because they think it's a waste of time." Father, Wajir

\section{Cost Effectiveness and Benefit Valuation:}

Figure 10 is a summary of the costs per intervention that were included in the midline report.

\section{FIGURE 10. Incremental and Intervention Annual Package Costs}

\begin{tabular}{|c|c|c|c|c|}
\hline & \multicolumn{2}{|c|}{ Mbera } & \multicolumn{2}{|c|}{ Wajir } \\
\hline & $\begin{array}{c}\text { Incremental } \\
\text { Annual Cost } \\
\text { (per beneficiary) }\end{array}$ & $\begin{array}{l}\text { Total Package } \\
\text { Annual Cost } \\
\text { (per beneficiary) }\end{array}$ & $\begin{array}{c}\text { Incremental } \\
\text { Annual Cost } \\
\text { (per beneficiary) }\end{array}$ & $\begin{array}{c}\text { Total Package } \\
\text { Annual Cost } \\
\text { (per beneficiary) }\end{array}$ \\
\hline $\begin{array}{l}\text { Violence } \\
\text { Prevention } \\
\text { Only }\end{array}$ & $\$ 33$ & $\$ 33$ & $\$ 116$ & $\$ 115$ \\
\hline$V+$ Education & $\$ 242$ & $\$ 275$ & $\$ 215$ & $\$ 332$ \\
\hline$V+E+$ Health & $\$ 98$ & $\$ 373$ & $\$ 250$ & $\$ 581$ \\
\hline $\begin{array}{l}\mathrm{V}+\mathrm{E}+\mathrm{H}+ \\
\text { Wealth } \\
\text { Creation }\end{array}$ & $\$ 39$ & $\$ 412$ & $\$ 115$ & $\$ 695$ \\
\hline
\end{tabular}

At midline, it was determined that the VEHW package presented good value for money as it made use of economies of scope via delivery of a four-intervention package and also delivered the widest range of positive effects at the end of the intervention. Two years later, when considering the quantitative data, it appears that the education intervention had the strongest impact on the longer-term effects on educational attainment and delayed childbearing. In addition, quantitatively, the VEHW package led to additional benefits not seen in other armsnamely long-term improvements in savings behavior (both Kibera and Wajir) and household economic status (in Kibera only). The qualitative data also speaks to girls feeling more empowered, and having improved selfconfidence, self-respect, self-worth, future education goals, social skills, and a place where they could share their challenges with others. Parents also commented on improved relationships with their daughters after they took part in the Safe Spaces component of AGI-K. However, this did not translate into quantitative impact, possibly because of measurement issues. Therefore, from a pure cost-effectiveness perspective using the quantitative results, the education intervention was the driver of the impact on the longer-term results. When considering the full combination of midline and endline, quantitative and qualitative results, value in the VEHW package can be seen.

\section{Benefit Valuation \\ AGI-K Cohort:}

Table 4 summarizes the results of the benefits valuation per girls for the actual girls in the AGI-K cohort. The total quantified benefits varies by site, and in Wajir, by schooling status, in line with the quantitative results presented above. It is clear from the results that, from a monetary perspective, out-of-school girls in Wajir benefited the most from AGI-K, in particular those girls who were out of school at baseline. This is in line with the theory of change, which posited that by keeping them in school, marriage and childbirth would be delayed, and many welfare, health, and economic benefits would be reaped. 
TABLE 4. Summary of total benefits per girl of AGI-K program-VE, VEH, and VEHW arms combined

\begin{tabular}{|l|c|}
\hline & Benefit per girl \\
\hline Wajir in-school girls at baseline & $\$ 11$ \\
\hline Wajir out-of-school girls at baseline & $\$ 94$ \\
\hline Kibera (all girls) & $\$ 55$ \\
\hline
\end{tabular}

NOTE: Benefit per girl only includes those girls in the intervention groups, not the control groups.

It must be noted that the above quantifications only include economic and health benefits. They exclude unquantifiable private benefits of increased knowledge, voice, agency, networks, empowerment, confidence, and self-esteem, and also the public good benefits as described above. This has the effect of underestimating monetary benefits.

The benefits are also dampened due to the fact that the prevalence of pregnancy in the control groups was much lower than the regional averages, perhaps because of improvements since the Kenya DHS 2014, thus giving rise to a low caseload on which to model the benefits. This could be significantly different in a different setting/ region/scale/duration. A longer program duration and/or longer follow-up study is likely to change prevalence figures and thus increase impact.

\section{AGI-K at scale:}

We estimated four scale-up scenarios, for a similar period of two years per girl:

1. All girls ages $10-14$ in Wajir (45,900 girls)

2. All girls ages $10-14$ in Kibera (17,007 girls)

3. All girls ages 10-14 in the following counties: Wajir, Garissa, Isiolo, Mandera, Marsabit, Samburu, Turkana, (573,228 girls)

4. All girls ages $10-14$ in Nairobi slums (242,000 girls)

For the ASAL counties the same assumptions were used in terms of being in school and out of school at baseline. For all scenarios, while it is not likely that all girls will be reached, the same approach was taken in AGI-K in which all girls in a certain age category were invited and the results reflect the impact at the population level, irrespective of who participated.

The results are displayed in Table 5. The unit benefit per girl figure is within the same range as that of the AGI-K program benefits, which is expected. The benefit figures for scale-up give a good indication of what program cost maximum threshold should be to break even, if one were to take a purely monetary valuation approach. The AGI-K costs were naturally higher than scale-up costs, which would be run through government systems (AGI-K was delivered through NGOs, which is likely to be a far more expensive model compared to government delivery). Moreover a significant proportion of AGI-K costs were fixed or set-up costs in nature, such as assessing schools, developing materials for training and curricula, creating monitoring and evaluation systems, and the establishment of the CCT protocols. If AGI-K was scaled up at the county level such fixed costs would not need to be incurred again, thus the overall budget would be significantly lower, providing a more even balance between costs and benefits. Also a longer timescale would allow fixed costs to be spread over time, thus also rebalancing costs versus benefits, and benefits/impacts would be higher with a longer timescale.

\section{Limitations}

While the overall study design is quite rigorous, there are a few potential sources of bias. The first is that the baseline sample could be biased from the overall population that it is intended to represent, because of nonresponse at baseline. Second, there could be differential attrition between baseline and endline by arm, which was not adjusted for in the analysis. This potential bias was explored, and in Kibera, girls in the V-only arm were more likely to be lost-to-follow-up as compared to the other three arms. In Wajir, girls in the V-only and VE arms, both in school and out-of-school at baseline, were more likely to be lost to follow-up than girls in the VEH and VEHW arms. In addition, 
TABLE 5. Scale-up Scenario Benefits

\begin{tabular}{|l|l|c|c|}
\hline & \multicolumn{1}{|c|}{ Scale-up Scenarios } & Total Benefits & Benefit per Girl \\
\hline 1 & All girls ages 10-14 in Wajir & $\$ 1,525,857$ & $\$ 33$ \\
1 b & All girls out of school 10-14 in Wajir & $\$ 1,161,950$ & $\$ 94$ \\
\hline 2 & All girls ages 10-14 in Kibera & $\$ 1,471,437$ & $\$ 55$ \\
\hline 3 & All girls ages 10-14 in the ASAL areas & $\$ 4,544,696$ & $\$ 11$ \\
3a & All girls in school 10-14 in the ASAL areas & $\$ 14,511,160$ & $\$ 94$ \\
\hline 3b & All girls out of school 10-14 in the ASAL areas & & $\$ 55$ \\
\hline 4 & All girls ages 10-14 in Nairobi slums & $\$ 13,272,129$ & \\
\hline
\end{tabular}

the girls are still relatively young at endline and therefore major transitions have not yet occurred for most. This could have the effect of widening or narrowing the impact given time; this is uncertain and not possible to predict at this point. The control group has violence-prevention measures, so it is not a pure control group. This may explain the low prevalence of pregnancies observed in the control, which has the effect of underestimating impact.

For the benefit valuation, given the nature of the behavior-change program and limitations of data, it is a partial analysis, as it is not possible to value all benefits, partially because some of the endline results are qualitative in nature and therefore unable to be assigned a monetary value. Therefore there is a natural underestimate in benefits, and assumptions in the modeling have been prudent.

In addition, this type of modeling is fraught with uncertainties, and missing data, attribution problems, and longterm and public good nature of benefits. All these things mean that assumptions have to be taken from external sources. The relatively short duration of two years reduces the accuracy of the results because not all girls have reached the age of 18 , so the prevalence of giving birth early could change after endline results. This risks a reduction in the robustness of the modeling. ${ }^{18}$

This estimation focuses on the above-mentioned private household benefits, as this is the only approach feasible in terms of using endline results in a meaningful way. Modeling society-wide public macroeconomic benefits is not feasible because there is no clear robust causal pathway underlying assumptions to link the AGI-K program with the demographic dividend, societal benefits, intergenerational benefits, not to mention the modeling complexities; attribution is a big barrier here. The AGI-K cohort of just under 7,000 girls over two years is a relatively small intervention. To have a non-negligible impact at a macro level would require transformation change brought about by scale-up, replication, or systemic change that would require a much larger cohort of girls over a longer timeframe. Moreover, such benefits would be far into the future, at least ten years from now, which would be significantly reduced due to discounting. Finally, this type of general equilibrium modeling is beyond the scope of this report.

${ }^{18}$ The standalone report includes sensitivity analysis to counteract this issue. 


\section{Conclusion}

\section{KEY TAKEAWAYS}

- $\quad$ The cash transfer is a key driver of the improvement in education outcomes, delaying sexual debut and pregnancy in Kibera, and delaying marriage and pregnancy in Wajir.

- Cash transfers can still be effective in the long term if delivered only during critical windows of vulnerability for girls and/or for particular sub-segments of girls.

- Girls empowerment groups may need to be carried out over longer periods of time in order to sustain the effect; should also be seen as a right.

- Targeting the intervention to particular sub-segments of girls is important-in Wajir, out-of-school girls benefited the most; in Kibera, girls in the midst of the transition from primary to secondary school.

- A multi-level, multi-sectoral approach to girls programming is a promising approach providing a wider range of outcomes as well as being more cost-effective than single-component interventions.

- $\quad$ The true benefit of the program will likely be realized when it is able to operate at scale, at lower costs.

Overall, the two-year follow-up results largely confirmed the AGI-K theory of change and held up the notion that an investment in early adolescents among the right groups of marginalized girls would have short-term benefits on asset accumulation, educational attainment, and household economic status that translated into longer-term impact on delaying childbearing. In addition, the causal mechanisms for delaying childbearing proposed-delaying sexual debut in Kibera and delaying marriage in Wajir-were also confirmed by the long-term results, albeit in Wajir only for the girls who were out of school at baseline.

The cash transfer appeared to be a key driver in the impact seen not only on education outcomes but also on delaying sexual debut and pregnancy in Kibera, as well as delaying marriage and pregnancy in Wajir. It appears that the path to these longer-term outcomes came largely through keeping girls in school in Kibera during the transition from primary to secondary school, and via getting girls who were out of school in Wajir into school, for many for the first time, and off the path to marriage.

However, there may still be value in offering the cash transfer together with girls empowerment groups that offer both health and economic empowerment. In particular, in the urban setting the economic components led to longterm, sustained improvements in savings behavior. Second, at the end of the two-year intervention, there were improvements in girls' confidence, voice, and sense of choice over their decisions. That the measures of empowerment did not show sustained impact two years after the programs suggests perhaps that maintaining social support for vulnerable girls and creating spaces in which they can learn about their rights and have opportunities to express themselves may need to be carried out over longer periods of time, whereas cash transfers can still be effective if delivered only during critical windows of vulnerability for girls and/or for particular subsegments of girls. Beyond that, offering girls health and life-skills training can also be considered a right, as learning about their body, sexual and reproductive health and rights (SRHR), and life-skills is mentioned in the United Nations Convention on the Rights of the Child. The cost-effectiveness calculations at midline (see Relevant Links, Midline Report) demonstrated that delivering the interventions in packages is better value for money than delivering them individually. Therefore, the fully combined package should still be considered based on impact, cost, and rights. 
Another clear takeaway from the results is that targeting the intervention to particular sub-segments of girls is important. For example, in Wajir the strong impact was for girls who were out of school at baseline, which was a significant proportion of the sample. From that a possible conclusion is that a program like AGI-K in ASAL areas must be sure to reach those girls who are out of school as a jump-start to getting them back into school and off the path to child marriage or those at risk of dropping out to ensure that they stay on that path. In Kibera, at midline the results on education were strongest for those in the final two years of primary school, and at endline the impact on delaying sexual debut was concentrated in the girls who were 13-15 years old at baseline. This suggests that perhaps in an urban informal settlement setting, the key sub-segment for target is those girls approaching mid-adolescence, about to enter that risky period of transitioning from primary to secondary school, and that the support during that window of vulnerability is key in keeping them on the path to completing secondary school and avoiding pregnancy in adolescence.

One of the key theories being tested was that it would take a multi-level, multi-sectoral program implemented in early adolescence to affect change in later adolescence. This means that the combination of interventions at girl, household, and community levels, addressing violence, education, health, and economic empowerment, would be needed to achieve higher-level results such as delayed childbearing. The evidence and experience of AGI-K suggests that this theory may be true, and that neither single-intervention programs nor programs that focus all their interventions on one layer of the girls' ecosystem will have the necessary change in early adolescence to lead to longer-term impact. It is likely that the true benefit, in particular from a cost perspective, will be realized when the critical program components are able to operate at scale, at lower costs, and combine longer-term programming to sustain empowerment outcomes, with targeted cash incentives for vulnerable sub-populations of girls at their times of greatest risk. 


\section{Relevant Links}

Study Website:

https://www.popcouncil.org/research/adolescent-girls-initiative-action-research-program

Baseline Report:

https://www.popcouncil.org/uploads/pdfs/2015PGY_AGI-K_BaselineReport.pdf

Midline Results Report:

https://www.popcouncil.org/research/adolescent-girls-initiative-action-research-program

Kibera Health and Life Skills Curriculum:

https://www.popcouncil.org/uploads/pdfs/2015PGY_AGI-K_HealthLifeCurriculum_Kibera.pdf

Kibera Financial Education Curriculum:

https://www.popcouncil.org/uploads/pdfs/2015PGY_AGI-K_FinancialCurriculum_Kibera.pdf

Wajir Health and Life Skills Curriculum:

https://www.popcouncil.org/uploads/pdfs/2015PGY_AGI-K_HealthLifeCurriculum_Wajir.pdf

Wajir Financial Education Curriculum:

https://www.popcouncil.org/uploads/pdfs/2015PGY_AGI-K_FinancialCurriculum_Wajir.pdf

Wajir Audio Scripts for Health and Life Skills Curriculum:

https://www.popcouncil.org/uploads/pdfs/2018PGY_AGI-K_HLS-TrainingScriptWajir.pdf

Wajir Audio Scripts for Financial Literacy Curriculum:

https://www.popcouncil.org/uploads/pdfs/2018PGY_AGI-K_FE-TrainingScriptWajir.pdf

Adolescent Girls Initiative - Kenya Data Repository:

https://www.popcouncil.org/research/adolescent-girls-initiative-kenya-agi-k 


\section{Appendix A}

\section{AGI-K National External Advisory Committee}

1. Kenya Women Parliamentary Association (KEWOPA)

2. National Gender and Equality Commission

3. Gender Directorate, Ministry of Devolution and Planning

4. Department of Children's Services, Ministry of Labour, Social Security \& Services

5. Department of Policy, Partnership and EAC, Ministry of Education

6. Reproductive and Maternal Health Services, Ministry of Health

7. Department of Health, Wajir County

8. County Department/Sector of Education, Wajir County

9. Kadhi, Judicial Service Commission, Wajir County

10. Wajir County Government, Humanitarian Coordinator

11. Kenya Post Office Savings Bank (Postbank)

12. Equity Bank/Equity Group Foundation

13. Gender and Social Development, Kenya Private Sector Alliance

14. Footprints Africa Foundation

15. UNICEF Kenya

16. UN Women

17. UNFPA, Reproductive Health and Youth

18. UNESCO

19. ALDEF - Wajir Local NGO

20. WASDA - Wajir Local NGO

21. Center for Rights Education and Awareness (CREAW)

22. Girl Child Network

23. Center for the Study of Adolescence (CSA)

24. Association of Media Women in Kenya

25. Department of Community Health, University of Nairobi

\section{AGI-K Kibera External Advisory Committee}

1 Office of the MP, Kibra Constituency

2. Nairobi County Assembly

3. Department of Children's Services, District Children's Officer

4. Deputy Gender Officer - Kibera, Langata Subcounty

5. County Education Officer, Nairobi County

6. District Education Officer, Langata Subcounty

7. Public Health Officer, Langata Subcounty

8. District Health Officer, Langata Subcounty

9. Assistant District Health Officer, Langata Subcounty

10. District Commissioner, National Administration

11. Equity Bank, Kibera Branch 
12.

13. Kenya Primary School Heads Association - Langata Constituency

14. Kibera Paralegal Network

15. Carolina for Kibera

16. Undugu Society

17. Shining Hope for Communities Lea Toto

18. Kibera Informal Settlements Association

19. SAVO Foundation CBO

20. Global Communities

21 Umande Trust

22. Concern Worldwide

23. DARAJA

24. African Network for the Prevention and Protection against Child Abuse and Neglect

25. Centre for Rights Education and Awareness

\section{AGI-K Wajir External Advisory Committee}

1. Department of Children's Services, Wajir County

2. Wajir County Government, Humanitarian Coordinator

3. County Director of Education, Wajir County

4. County Health Director, Wajir County

5. County Reproductive Health Coordinator, Wajir County

6. National Drought Management Authority, Hunger Safety Net Program, Secretariat

7. Gender and Social Services, Wajir County

8. Chairman, Court User Committee, Judicial Service Commission, Wajir County

9. Teachers Service Commission, County Director

10. Community Strategy Focal Point, Wajir County, Ministry of Health

11. County Executive Committee Member - Education, Wajir County

12. Equity Bank - Wajir Branch

13. Kenya Primary School Heads Association - Wajir

14. Kadhi, Judicial Service Commission, Wajir County

15. Council of Imam Preachers of Kenya

16. Supreme Council of Kenya Muslims

17. Wajir Paralegal Network

18. Discovery Learning Alliance

19. OXFAM

20. Islamic Relief

21. WASDA

22. ALDEF

23. Mercy Corps

24. Human Rights Watch 


\section{Appendix B: Intent-to-Treat (ITT) Endline Indicators Analysis Tables (Kibera)}

Austrian, K., Soler-Hampejsek, E., Kangwana, B., Maddox, N., Wado, Y., Abuya, B., Shah, V., and Maluccio, J. 2020. "Adolescent Girls Initiative-Kenya: Endline Evaluation Report." Nairobi: Population Council. https://doi.org/10.7910/ DVN/94U224, Harvard Dataverse. 


\section{Appendix C: Intent-to-Treat (ITT) Endline Indicators Analysis Tables (Wajir)}

Austrian, K., Soler-Hampejsek, E., Kangwana, B., Maddox, N., Wado, Y., Abuya, B., Shah, V., and Maluccio, J. 2020. “Adolescent Girls Initiative-Kenya: Endline Evaluation Report." Nairobi: Population Council. https://doi.org/10.7910/ DVN/94U224, Harvard Dataverse. 


\section{Appendix D: \\ Summary of Baseline and Midline Study Findings}

While this report focuses on the endline results from data collected in 2019, it builds on data collected in 2015 (baseline) and 2017 (midline). Below is a summary of the key phases of the research and findings after each major round of data collection.

\section{BASELINE}

Data was collected between February - May 2015 in both Kibera and Wajir among girls ages 11-14 and their households. The data collected gave a picture of the status of girls at the start of the AGI-K program. Baseline results from Kibera and Wajir suggested that although young adolescents face a myriad of challenges, the majority had not yet experienced risks associated with poor sexual and reproductive health outcomes. Intervening in the different sectors (education, wealth, health, and violence prevention) therefore had the potential to delay or prevent negative outcomes as adolescents made the transition to adulthood in resource-constrained settings. Overall, there were stark differences between Kibera (urban slum) and Wajir (rural area) in all four sectors. The differences between Nairobi and Wajir justify the importance of looking at these as separate sub-studies.

\section{Education}

One in four girls in Wajir had never attended school compared to less than 1\% of girls in Kibera. Similarly, about a quarter of the girls in Wajir were in the expected class relative to their age, compared to $71 \%$ of girls in Kibera. However, in Kibera, older girls were more likely to be behind in their schooling, indicating that progression through grades might also be poor. The AGI-K education intervention, a cash transfer conditioned on enrollment and attendance, therefore sought to increase enrollment in Wajir and improve grade progression and transition to secondary school in both Kibera and Wajir.

\section{Wealth Creation}

Overall, girls had low levels of financial literacy and savings. Although over $40 \%$ of girls in Kibera had access to cash, which they spent on their daily needs in the previous year, fewer than $30 \%$ had any savings. In Wajir, less than $1 \%$ of girls reported having savings. The low levels observed in the baseline results suggested a critical need for the AGI-K wealth-creation interventions, which aimed to build girls' economic well-being by equipping them with moneymanagement skills and teaching them to save at a young age.

\section{Health}

Low levels of sexual activity were found among study participants, with only $2 \%$ of girls in both Kibera and Wajir having already initiated sex. (All sexually active girls in Wajir were married.) These low levels of sexual initiation at baseline mean that more girls stand to benefit from the interventions to delay sexual initiation and the timing of first birth. The baseline results also highlighted limited menstrual knowledge among adolescents in both settings, but especially in Wajir. Overall, results highlighted the need to strengthen sexual and reproductive health education for very young adolescents and to equip them with culturally relevant, accurate, and age-appropriate information. The AGI-K health intervention then delivered this information using the Safe Spaces model, which has been shown to have a positive impact on young people, including increased sexual and reproductive health knowledge in both rural and urban settings.

\section{Violence Prevention}

About a third of girls in Kibera reported that they had experienced emotional, physical, and sexual violence. In contrast, fewer than 5\% of girls in Wajir reported that they had experienced any of these forms of violence. Nonetheless, almost one-third of girls in Wajir reported that they felt scared of being raped and over 1 in 10 said a boy or man had touched them indecently in the past six months. Overall, there was general acceptance of female genital mutilation/cutting (FGM/C) in Wajir, as the practice is widespread and common in the region. 
Equal proportions of young girls in both Kibera and Wajir agreed that a husband is justified in beating a wife for at least one reason, however a higher proportion of girls in Wajir agreed with reasons such as "going out without telling him," "refusing to have sexual intercourse with him," and "burning food." Results suggest ingrained gender norms around the status of women in the communities, which may be influencing girls' attitudes as well as their perceived Iow status relative to their male counterparts. The AGI-K violence-prevention intervention, community conversations focused on improving the value of girls within the community, sought to improve the enabling environment for girls.

To summarize, though the results from the baseline study highlighted a number of negative issues affecting young girls in Kibera and Wajir, results also showed potential promise in investing in young adolescent girls. By building girls' assets through a combination of education, social, health, and economic interventions, there was potential to change their life course. The data generated from AGI-K will help us understand the kinds of interventions that are best positioned to help us achieve this goal.

To read more about the details of how the sample was created or the data was collected, please read the $\underline{A G I-K ~ s t u d y}$ protocol paper or the full baseline report.

\section{MIDLINE}

The objective of the midline report was to describe and compare the impact of the different program packages at the end of the two-year program when girls were 13-16 years old. Girls from the baseline sample were re-interviewed, along with the household head. Approximately $91 \%$ of the baseline sample in Kibera and $89 \%$ in Wajir were reinterviewed. The key findings were as follows:

\section{Kibera}

The conditional cash transfer (CCT) improved the rates of primary school completion and the transition to secondary school for girls who were in the final two years of primary school at the start of the intervention. These results were largest and statistically significant for girls who received the full program package. In addition, the cash transfer improved household wealth status vis-à-vis cash liquidity and relative wealth status for all three program packages that included the education intervention.

The health intervention (weekly girls' groups) resulted in clear improvements for girls in the two program packages with the health intervention on contraception knowledge, SRH knowledge, condom self-efficacy, help-seeking selfefficacy, and social safety nets (both among age-mates and with female adults). However, the intervention did not have an effect on attitudes around the acceptability of intimate partner violence or equitable gender norms.

The wealth creation intervention had clear positive impacts on levels of financial literacy, savings frequency, and savings amount for girls in the full program package.

While the effect of the violence prevention intervention on its own was not evaluated due to the evaluation design (Vonly arm served as the control), when packaged together with the other interventions, there was a positive effect in reducing girls' experience of physical, emotional, and sexual violence by males in the past year.

Important to note is that for girls who actively participated in the safe spaces (health and wealth creation), the impact not only on their health and wealth outcomes was larger, but also on their education outcomes - implying that participating in girls' groups with combined health and economic content had spillover effects onto their educational attainment.

\section{Wajir}

In Wajir, where about a quarter of girls were out of school at baseline, the education CCT had a large impact on primary school enrollment and retention. These impacts held true for all three arms receiving the education CCT. However, the CCT did not translate into increases in household economic status, suggesting that the Wajir households spent more of the transfer on daily household needs as opposed to cash and asset accumulation. 
The health intervention with the health, life skills, and nutrition curriculum, did not increase knowledge for girls in the VEH and VEHW arms on contraception, menstrual health, HIV/STIs, or nutrition. For the girls in the VEHW arm there were small but positive effects on help-seeking self-efficacy. For the girls who actively participated in the VEHW arm, there was also a positive effect on general self-efficacy. There was no change in acceptability of violence. There was some positive change on equitable gender attitudes related to men's and women's roles, for example who should make decisions in a household or whether a boy's education should be prioritized over a girl's where there is a lack of resources.

The financial literacy and savings activities had a positive impact on the girls receiving the full program package in Wajir. There was a large increase in financial literacy scores and savings frequency and amount. For girls who participated actively in the girls' group meetings/safe spaces, the effect was twice as large.

It appears that violence is significantly underreported as only 3\% of girls at baseline and $4 \%$ of girls at midline reported experiencing violence in the past one year. Validation meetings with local stakeholders in Wajir confirm that this is grossly underreported, likely because of significant taboos around disclosing and discussing violence. Therefore, even if the program did have an effect on the experience of violence, it is not possible to detect. However, household-level norms around expectations of girls' educational attainment improved for those households in the VE, VEH and VEHW arms and the percent of households that expected their daughters to marry before 18 dropped in both the VEH and VEHW arms.

\section{KEY LESSONS DRAWN AT MIDLINE - END OF INTERVENTION}

Overall the AGI-K program had positive effects on short- and medium-term education, social, health, and economic assets.

\section{Education}

Overall, the effects of the conditional cash transfer were positive, but the particular area of impact was dependent on the baseline status of girls' education in each site. In Kibera, because the cash transfer was beneficial for those girls completing primary and transitioning to secondary school, moving forward, narrowing the scope of the recipients of the CCT, from girls in urban informal settlements to those nearing the transition from primary to secondary school, will be more cost-effective. In Wajir, CCT had large positive effects on bringing out-of-school girls into school and ensuring that those who are behind in their schooling relative to their age remained enrolled; this implies that future CCTs in settings such as Wajir should therefore target those segments of adolescents.

\section{Health}

In Kibera, the safe spaces groups impacted the girls as expected, improving knowledge, self-efficacy, and social safety nets. Even more promising is the positive impact of active participation in the safe spaces groups not only on health outcomes, but also on education outcomes. The results suggest that being an active part of a girl's empowerment club, which focus on improving health knowledge, self-efficacy, and social safety nets, goes on to further improve education outcomes. This makes the investment in the cost of establishing and maintaining the safe spaces platform good value for money.

In Wajir however, the health intervention (girls' groups with health content) did not have the hypothesized impact. Validation meetings with key stakeholders and implementers in Wajir suggest that despite that community sensitization, mentor training, audio training sessions, and monitoring, the community, and specifically the mentors themselves, were unwilling to deliver the sessions on sexual and reproductive health topics with girls. The objection was not with the delivery channel, as the groups met, and the economic content did have an impact, but to the SRHfocused content itself. The implication is that perhaps in very socially conservative settings with little infrastructure and economic resources, the entry into the community should be first via improvements in education, wealth creation and infrastructure. This recommendation on entry points is further reflected by the way in which action plans were prioritized by the community conversation groups. In Kibera, community conversation groups focused on creating resource centers and learning opportunities for girls, that is, activities for girls, while in Wajir, they focused on making improvements to school infrastructure. However, even despite conservative attitudes toward SRH in Wajir, there were 
small improvements in self-efficacy and gender norms - both at the girl and household levels. This suggests that the safe spaces groups could be a platform to positively change SRH outcomes, but the process through which the community will accept SRH-focused content to enable this to happen is longer than the AGI-K program allows.

\section{Wealth Creation}

The wealth creation intervention led to some of the largest and most consistent changes in both sites, indicating that financial education and savings for girls are both accepted and impactful. The combination of financial education sessions with savings mechanisms further supports the literature in that having the opportunity to immediately put into practice newly acquired skills helps financial literacy training to "stick." The endline survey will confirm whether the improvement in economic assets for girls will have a long-term influence on the timing and choices around marriage and sexual relationships.

The cost of layering on the wealth creation intervention to the safe spaces platform was relatively minimal, and the education effect sizes were greater in the arm that included wealth creation as compared to the arms that did not Therefore, the recommendation for future programs would be to couple the health content with financial literacy and savings opportunities. In addition, in areas where formal financial services are accessible, creating opportunities for adolescent girls to open and own their own savings accounts is important for financial institutions in Kenya to consider in order to improve savings behaviors.

\section{Violence Prevention}

Although the study design does not allow us to evaluate the impact of the community-based intervention on its own, we still believe that it is important vis-à-vis the theory of change to work at multiple levels of a girls' ecosystem and couple household and girl-level interventions to address girls' empowerment with a community component. Addressing and understanding the enabling environment for girls is important so that girls and their families can leverage improvements in education, skills, and knowledge, which will in turn eventually translate into longer-term change. One explanation is that creating space at the community level in Wajir opened up space for the positive changes in gender norms at the household level driven by the other interventions.

\section{Cost Effectiveness}

The conclusion from the midline results on value for money is that when the objective is to maximize girls' welfare on a range of indicators, it is more cost-effective to use a multi-sectoral approach. That is, by undertaking education interventions alongside wealth and health interventions, where implementing each intervention component costs less when packaged, a wider range of outcomes are achieved.

The evidence emerging from the AGI-K midline survey is encouraging. It has shown that positive change is possible in two very different, marginalized settings in Kenya. It reinforces the point that context matters and that the pathways to asset-building and empowerment vary in different settings. Future interventions targeting vulnerable girls need to take into account the setting and focus on specific segments of girls in order to maximize efficiency of spending resources - particularly on education-support programs. The evidence also reinforces the theory that addressing empowerment for adolescent girls through a multi-sectoral approach leads to larger impact and that "cash plus," or supplementing household economic incentives with additional social, health, and asset building for girls themselves, provides the best value for money when looking across education, health, and economic outcomes.

For more details on the midline results, please read the midline evaluation report. 


\section{Appendix E: Research Uptake}

The AGI-K team understands that its research, no matter how relevant, means little if potential end-users of the information are not engaged from the design of the project to its implementation and evaluation. With the ultimate aim of identifying the most cost-effective packages of interventions for adolescent girls in Kenya, our research uptake goals are to:

- Influence budget allocations/policy decisions at county and national levels in Kenya

- Influence external funding decisions within Kenya for future adolescent girls programs

- Influence funding of similar programs in other countries in the region

One of the first steps taken by the project team to enhance the research uptake process was the establishment of three multi-sectoral External Advisory Committees (EAC). The national EAC is comprised of members from national and county government (Wajir), national NGOs working on adolescent girl issues, multi-laterals and private sector representatives. The Wajir and Kibera EACs are comprised of county and sub-county government representatives, local Community Based Organizations (CBOs) and community leaders. The national EAC was involved in the project inception phase and was critical in providing advice on the implementation strategy, the community sensitization plan, strategies to ensure interventions are sustainable and scalable and feedback on the preliminary midline results. The local EACs have been a critical part of the community sensitization and community buy-in processes in both sites, as well as providing local insight and interpretation of the midline findings. The EACs are instrumental in promoting the uptake of research findings and the use of results to influence policy and scale-up of effective strategies at both national and county levels.

The results from the AGI-K evaluation will be relevant for a wide range of audiences at the sub-national, national and global levels. These different users of the research each require a different approach in the research uptake.

\section{County (Subnational) Level}

Working with county governments on a three-step process: 1) engage them with a range of data on the situation of adolescent girls in their county and what we know about what interventions have evidence to show that they work (or do not work), with AGI-K as a central example of "what works"; 2) discuss what intervention components can address challenges in the particular county and can be taken up via which county structures; 3 ) develop and implement a costed implementation plan.

\section{National Level}

At the national level we will engage within the individual ministries, as well as national level program implementers and donors. These stakeholders have been engaged since the start of the study so that they are invested in and anticipating the findings. As the endline results are available we will hold a series of one-on-one meetings within individual ministries to engage on what the policy recommendation coming from the results are and how they might be integrated into policy agendas. AGI-K staff also take part in several technical working groups to ensure that the data helps to shape conversations, drafting of guidelines, etc. We will also hold dissemination events with program implementers so that we translate the evidence into concrete program recommendations that can be taken up in current or future programs for adolescents in Kenya.

\section{Global Level}

As the evidence generated by AGI-K is at a high level of scientific rigor, the learning should be included in the global body of evidence and guidance on what works for adolescent girls. To ensure that global stakeholders - from multilaterals, bi-lateral, foundations and international organizations - we will hold webinars and present at global conferences and other forums. 
To ensure that there are written materials that speak to all the full range of audiences, AGI-K will produce a variety of research products to communicate the findings. These include a website, peer-reviewed journal articles, datasets corresponding survey instruments, policy briefs/fact sheets and power-point presentations tailored to particular key individuals/audiences. 


\section{References}

Austrian, K. and D. Ghati. 2010. Girl-Centered Program Design: A Toolkit to Develop, Strengthen and Expand Adolescent Girls Programs. Nairobi: Population Council.

Austrian, K., E. Muthengi, J. Mumah, E. Soler-Hampejsek, C. Kabiru, B. Abuya, and J. Maluccio. 2016. "Adolescent Girls Initiative-Kenya: Study Protocol,” BMC Public Health 16:210. DOI 10.1186/s12889-016-2888-1

Blum, R.W., F.I. Bastos, C.W. Kabiru, L.C. Le. 2012. “Adolescent health in the $21^{\text {st }}$ century,” The Lancet. 379(9826): 1567-1568.

Bruce, J. and J. Sebstad. 2005. "Building assets for safe, productive lives: A report on a workshop on adolescent girls' livelihoods." Presented at Adolescent Girls Livelihoods Meeting. New York, April 7-8, 2004. Population Council.

Kenya National Bureau of Statistics (KNBS) and ICF International. 2015. Kenya Demographic and Health Survey 2014. Rockville, MD: KNBS and ICF International.

Wodon, Q., C. Male, A. Nayihouba, A. Onagoruwa, A. Savadogo, A. Yedan, J. Edmeades, A. Kes, N. John, L. Murithi, M. Steinhaus, and S. Petroni 2017. Economic Impacts of Child Marriage: Global Synthesis Report. Washington, DC: The World Bank and International Center for Research on Women. 